\title{
Total Synthesis of Jimenezin via an Intramolecular Allylboration
}

\author{
Nina G. Bandur, David Brückner, Reinhard W. Hoffmann, and Ulrich Koert \\ Fachbereich Chemie, Philipps-Universität Marburg, Hans-Meerwein-Strasse, 35043 Marburg, \\ Germany
}

\section{SUPPORTING INFORMATION}

\section{General Methods and Materials}

All non-aqueous reactions were carried out using flame-dried glassware in an argon atmosphere. All solvents were distilled by rotary evaporation. Solvents for non-aqueous reactions were dried as follows prior to use: $\mathrm{THF}$ and $\mathrm{Et}_{2} \mathrm{O}$ were dried with $\mathrm{KOH}$ and subsequently distilled from sodium/benzophenone, respectively from a potassium/sodium alloy $(\mathrm{K} / \mathrm{Na} 4: 1) ; \mathrm{CH}_{2} \mathrm{Cl}_{2}, \mathrm{DIEA}$ and pentane were distilled from $\mathrm{CaH}_{2} ; \mathrm{MeCN}$ and pyridine were distilled from $\mathrm{CaH}_{2}$ or purchased from Acros (ultra dry quality) $\mathrm{CHCl}_{3}$ (for measuring optical rotations) was dried by passage through basic alumina, $\mathrm{MeOH}$ was dried by refluxing with $\mathrm{Mg}$-turnings $(5 \mathrm{~g} / \mathrm{L})$ and subsequent distillation; acetone and DMSO were purchased from Acros (ultra dry quality). All commercially available reagents and reactants were used without purification unless otherwise noted. Pinacole borane was prepared from pinacole and borane dimethyl sulfide complex and purified by condensation. ${ }^{1}$ The concentrations of organolithium and Grignard reagents were determined by the method of Watson. ${ }^{2}$ Reactions were monitored by thin layer chromatography (TLC) using Merck Silica Gel $60 \mathrm{~F}_{245}$ glass-plates and visualized by fluorescence quenching under UV-light. In addition, TLC-plates were stained using a cerium sulfate / phosphomolybdic acid stain. Chromatographic purification of products was performed on Merck Silica Gel 60 (230-400 mesh) unless otherwise noted using a forced flow of eluents. Neutral silica was

\footnotetext{
${ }^{1}$ Tucker, C. E.; Davidson, J.; Knochel, P. J. Org. Chem. 1992, 57, 3482.

${ }^{2}$ Watson, S.C.; Eastham, J. F. J. Organomet. Chem. 1967, 9, 165.
} 
purchased from Fuji Silysia (Chromatorex MB 100-40/75). Concentration under reduced pressure was performed by rotary evaporation at $40^{\circ} \mathrm{C}$ and the appropriate pressure. Yields refer to purified and spectroscopically pure products unless otherwise noted. Optical rotations were measured on a Perkin-Elmer 241 polarimeter using dried solvents and a $1 \mathrm{dm}$ path length cell. IR spectra were recorded on a Bruker IFS 200 or a Nicolet Magna-IR 750 spectrometer. The absorption bands are given in wave numbers $\left(\mathrm{cm}^{-1}\right)$, Intensities are reported as follows: $\mathrm{s}=$ strong, $\mathrm{m}=$ medium, $\mathrm{w}=$ weak, $\mathrm{br}=$ broad band. NMR-spectra were recorded on a Bruker ARX300 or DRX500 spectrometer at room temperature. Chemical shifts are reported in ppm with the solvent resonance as internal standard. Data are reported as follows: $\mathrm{s}=$ singlet, $\mathrm{d}=$ dublet, $\mathrm{t}=$ triplet, $\mathrm{q} i=$ quintet, $\mathrm{m}=$ multiplet, $\mathrm{m}_{\mathrm{c}}=$ symmetrical multiplet, $\mathrm{b}=$ broad signal, $\mathrm{p}=$ pseudo. Mass spectra were recorded on a Finnigan MAT TSQ 700 or MAT 95S (both mass service of Philipps-Universität Marburg) or an Applied Biosystems Model Q-Star (Prof. Marahiel, Philipps-Universität Marburg). Elemental analyses were determined on a Heraeus CHN-Rapid (Philipps-Universität Marburg).

\section{Experimental Procedures and Compound Characterization}

\section{(S)-3-Benzyloxy-dihydro-furan-2-ol (5)}

A solution of lactone $4(355 \mathrm{mg}, 3.47 \mathrm{mmol})$ and benzyl-2,2,2-trichloroacetimidate $(774 \mu \mathrm{L}$, $4.16 \mathrm{mmol})$ in $\mathrm{CH}_{2} \mathrm{Cl}_{2} /$ pentane $(1: 1,7 \mathrm{~mL})$ was cooled to $0^{\circ} \mathrm{C}$ and triflic acid $(15 \mu \mathrm{L}$, $0.17 \mathrm{mmol}$ ) was added. After stirring overnight at $\mathrm{rt}$ the solid was filtered off, the solution was diluted with TBME $(10 \mathrm{~mL})$ and washed with sat. $\mathrm{NaHCO}_{3}$-solution. The layers were separated and the aqueous layer was extracted with TBME $(3 \times 15 \mathrm{~mL})$. The organic layers were pooled and dried with $\mathrm{Na}_{2} \mathrm{SO}_{4}$. Purification by flash chromatography on silica (pentane $/ \mathrm{CH}_{2} \mathrm{Cl}_{2} / \mathrm{TBME}$ 10:10:1) gave the benzyloxy-lactone $(519 \mathrm{mg}, 2.71 \mathrm{mmol}, 78 \%)$ as a pale yellow oil. $R_{\mathrm{f}}=0.27$

(PE/acetone 4:1). $[\alpha]_{\mathrm{D}}=-100.3\left(\mathrm{c}=1.19, \mathrm{CHCl}_{3}, \vartheta=24^{\circ} \mathrm{C}\right) .{ }^{1} \mathrm{H}-\mathrm{NMR}\left(300 \mathrm{MHz}, \mathrm{CDCl}_{3}\right)$ : $\delta=7.42-7.15(\mathrm{~m}, 5 \mathrm{H}), 4.94(\mathrm{~d}, J=11.8 \mathrm{~Hz}, 1 \mathrm{H}), 4.73(\mathrm{~d}, J=11.8 \mathrm{~Hz}, 1 \mathrm{H}), 4.42$ (ddd, $J=9.1$, $8.1,6.9 \mathrm{~Hz}, 1 \mathrm{H}), 4.21$ (ddd, $J=9.1,8.1,6.9 \mathrm{~Hz}, 1 \mathrm{H}), 4.18$ (t, $J=7.8 \mathrm{~Hz}, 1 \mathrm{H}$ ), 2.46 (dddd, $J=13.0,7.8,6.9,4.4 \mathrm{~Hz}, 1 \mathrm{H}), 2.28(\mathrm{qd}, J=13.0,8.0 \mathrm{~Hz}, 1 \mathrm{H}) .{ }^{13} \mathrm{C}-\mathrm{NMR}\left(75 \mathrm{MHz}, \mathrm{CDCl}_{3}\right)$ : $\delta=175.0,136.9,128.5$ (2C), 128.09 (2C), 128.06 (2C), $72.472 .1,65.4,29.8$. 
The benzyloxy lactone $(1.51 \mathrm{~g}, 7.83 \mathrm{mmol})$ was dissolved in THF $(40 \mathrm{~mL})$ and cooled to $-78{ }^{\circ} \mathrm{C}$. DIBAH (1 $\mathrm{M}$ in hexane, $8.6 \mathrm{~mL}, 8.61 \mathrm{mmol})$ was added dropwise and the mixture was stirred at $-78{ }^{\circ} \mathrm{C}$ for $4 \mathrm{~h}$ and then added to a $1 \mathrm{M} \mathrm{K} / \mathrm{Na}$-tartrate solution $(30 \mathrm{~mL})$. After addition of TBME $(30 \mathrm{~mL})$ the mixture was stirred for $30 \mathrm{~min}$ at $\mathrm{rt}$. Extraction of the aqueous layer with TBME $(3 \times 30 \mathrm{~mL})$ and drying with $\mathrm{Na}_{2} \mathrm{SO}_{4}$ followed by flash chromatography on silica (pentane/Et ${ }_{2} \mathrm{O}$ 1:1) afforded the lactole 5 (1.46 g, $7.52 \mathrm{mmol}, 96 \%$, anomeric mixture of $65: 35$ revealed by ${ }^{1} \mathrm{H}$ $\mathrm{NMR}$ ) as a colorless oil. $R_{\mathrm{f}}=0.24$ (pentane/TBME 1:1). $[\alpha]_{\mathrm{D}}=+23.9$ (c=1.09, $\mathrm{CHCl}_{3}$, $\left.\vartheta=25^{\circ} \mathrm{C}\right) .{ }^{1} \mathrm{H}-\mathrm{NMR}\left(300 \mathrm{MHz}, \mathrm{CDCl}_{3}\right): \delta=7.39-7.24(\mathrm{~m}, 5 \mathrm{H}), 5.44(\mathrm{~d}, J=2.4 \mathrm{~Hz}, 0.65 \mathrm{H}), 5.32$ $(\mathrm{dd}, J=7.6,4.2 \mathrm{~Hz}, 0.35 \mathrm{H}), 4.66-4.51(\mathrm{~m}, 2 \mathrm{H}), 4.11-3.98(\mathrm{~m}, 2.65 \mathrm{H}), 3.93$ (d, $J=7.8 \mathrm{~Hz}$, $0.35 \mathrm{H}), 3.82(\mathrm{ddd}, J=8.3,7.8,5.6 \mathrm{~Hz}, 0.35 \mathrm{H}), 3.34(\mathrm{~d}, J=3.2 \mathrm{~Hz}, 0.65 \mathrm{H}), 2.29-2.14(\mathrm{~m}, 0.65 \mathrm{H})$, 2.13-1.93 (m, 1.35H). ${ }^{13} \mathrm{C}-\mathrm{NMR}\left(75 \mathrm{MHz}, \mathrm{CDCl}_{3}\right): \delta=137.8,137.1,128.5(2 \mathrm{C}), 128.4(2 \mathrm{C})$, 128.0, 127.8, 127.7 (2C), 127.6 (2C), 100.6, 96.1, 83.3, 78.0, 72.3, 71.3, 66.9, 64.7, 29.74, 29.69. Analysis: calcd. for $\mathrm{C}_{11} \mathrm{H}_{14} \mathrm{O}_{3}$ : C 68.02, $\mathrm{H}$ 7.27; found: C 68.08, H 6.96.

\section{[(3S,4S)-3-Benzyloxy-4-ethynyloxy-7,7-dimethoxy-heptyloxy]-tert-butyl-dimethyl-silane (6)}

A Grignard-species ${ }^{3}$ was prepared from Mg-turnings (525 mg, 21.6 mmol) and 3bromopropionic aldehyde dimethylacetale ${ }^{4}(3.29 \mathrm{~g}, 18.0 \mathrm{mmol})$ in THF $(18 \mathrm{~mL})$. After evaporation of the THF the oily residue was dissolved in $\mathrm{CH}_{2} \mathrm{Cl}_{2}$ and used immediately.

A solution of lactole $5(1.15 \mathrm{~g}, 5.92 \mathrm{mmol})$ in $\mathrm{CH}_{2} \mathrm{Cl}_{2}$ was treated with $\mathrm{MgBr}_{2} \cdot \mathrm{OEt}_{2}(2.45 \mathrm{M}$ in $\mathrm{Et}_{2} \mathrm{O}, 2.7 \mathrm{~mL}, 6.61 \mathrm{mmol}$ ), freshly prepared from Mg-turnings and 1,2-dibromoethane, and stirred for $1 \mathrm{~h}$ at $\mathrm{rt}$. Subsequently the freshly prepared Grignard-solution was added to the mixture at $0{ }^{\circ} \mathrm{C}$ and it was stirred for $24 \mathrm{~h}$ at $\mathrm{rt}$ and then diluted with $50 \mathrm{~mL}$ TBME. Aqueous workup using sat. $\mathrm{NaHCO}_{3}$-solution $(30 \mathrm{~mL})$ and TBME $(3 \times 30 \mathrm{~mL})$ and drying of the combined organic extracts with $\mathrm{Na}_{2} \mathrm{SO}_{4}$ followed by flash chromatography on silica neutralized with $\mathrm{Et}_{3} \mathrm{~N}$ (TBME/MeOH 20:1) afforded the diol (dr 99:1, $\left.1.44 \mathrm{~g}, 4.85 \mathrm{mmol}, 82 \%\right)$ as a colorless oil. The stereoselectivity was determined after the next step, the relative stereochemistry

\footnotetext{
${ }^{3}$ Molander, G. A.; Losada, C. P. Tetrahedron 1998, 54, 5819.

${ }^{4}$ Lee, T. V.; Porter, J. R. Org. Synth. 1995, 72, 189.
} 
was also assigned after the next step using the Hoffmann-Landmann method. ${ }^{5} R_{\mathrm{f}}=0.41$ $\left(\mathrm{CH}_{2} \mathrm{Cl}_{2} / \mathrm{MeOH} 10: 1\right) .[\alpha]_{\mathrm{D}}=-3.45\left(\mathrm{c} 1.13, \mathrm{CHCl}_{3}, \vartheta 20^{\circ} \mathrm{C}\right) .{ }^{1} \mathrm{H}-\mathrm{NMR}\left(300 \mathrm{MHz}, \mathrm{CDCl}_{3}\right)$ : $\delta=7.38-7.13(\mathrm{~m}, 5 \mathrm{H}), 4.65(\mathrm{~d}, J=11.5 \mathrm{~Hz}, 1 \mathrm{H}), 4.55(\mathrm{~d}, J=11.5 \mathrm{~Hz}, 1 \mathrm{H}), 4.38(\mathrm{t}, J=5.5 \mathrm{~Hz}$, 1H), 3.82-3.60 (m, 3H), $3.54(\mathrm{~m}, 1 \mathrm{H}), 3.32$ (s, 3H), 3.31 (s, 3H), 2.97 (bs, 1H), 2.86 (bs, 1H), 2.00-1.47 (m, 6H). ${ }^{13} \mathrm{C}-\mathrm{NMR}\left(75 \mathrm{MHz}, \mathrm{CDCl}_{3}\right): \delta=138.0,128.2(2 \mathrm{C}), 127.7$ (2C), 127.6, 104.4, 79.6, 72.32, 72.29, 58.7, 52.8, 52.6, 32.8, 28.9, 27.6. HRMS (ESI): $\mathrm{m} / \mathrm{z}$ calcd. for $\mathrm{C}_{16} \mathrm{H}_{26} \mathrm{NaO}_{5}$ $\left(\mathrm{M}+\mathrm{Na}^{+}\right): 321.1678$, found: 321.1663 .

The diol (1.29 g, $4.33 \mathrm{mmol})$ and imidazole $(383 \mathrm{mg}, 5.63 \mathrm{mmol})$ were dissolved in $20 \mathrm{~mL}$ $\mathrm{CH}_{2} \mathrm{Cl}_{2}$ and cooled to $0{ }^{\circ} \mathrm{C}$. TBSCl (50 wt-\% in toluene, $1.44 \mathrm{~g}, 4.76 \mathrm{mmol}$ ) was added dropwise and the mixture was stirred for $1 \mathrm{~h}$ at $\mathrm{rt}$. The excess $\mathrm{TBSCl}$ was trapped by the addition of $\mathrm{MeOH}$ $(175 \mu \mathrm{L}, 4.33 \mathrm{mmol})$ and after $30 \mathrm{~min}$ TBME $(50 \mathrm{~mL})$ was added. Aqueous workup using sat. $\mathrm{NaHCO}_{3}$-solution and TBME $(3 \times 40 \mathrm{~mL})$ and drying of the combined organic layers with $\mathrm{Na}_{2} \mathrm{SO}_{4}$ followed by flash chromatography on silica neutralized with $\mathrm{Et}_{3} \mathrm{~N}$ (pentane/TBME 2:1) gave the secondary alcohol $(1.67 \mathrm{~g}, 4.03 \mathrm{mmol}, 93 \%)$ as a colorless oil. $R_{\mathrm{f}}=0.30$ (PE/TBME 1:1). $[\alpha]_{\mathrm{D}}-4.23\left(\mathrm{c}=1.18, \mathrm{CHCl}_{3}, \vartheta 20^{\circ} \mathrm{C}\right) .{ }^{1} \mathrm{H}-\mathrm{NMR}\left(300 \mathrm{MHz}, \mathrm{CDCl}_{3}\right): \delta=7.37-7.26(\mathrm{~m}, 5 \mathrm{H})$, 4.67 (d, $J=11.5 \mathrm{~Hz}, 1 \mathrm{H}), 4.53(\mathrm{~d}, J=11.5 \mathrm{~Hz}, 1 \mathrm{H}), 4.38$ (t, $J=5.5 \mathrm{~Hz}, 1 \mathrm{H}), 3.74$ (t, $J=6.2 \mathrm{~Hz}$, $1 \mathrm{H}), 3.60-3.46(\mathrm{~m}, 2 \mathrm{H}), 3.32(\mathrm{~s}, 3 \mathrm{H}), 3.31(\mathrm{~s}, 3 \mathrm{H}), 2.69$ (d, J=5.4 Hz, 1H), 1.93-1.45 (m, 6H), $0.90(\mathrm{~s}, 9 \mathrm{H}), 0.06(\mathrm{~s}, 6 \mathrm{H}) .{ }^{13} \mathrm{C}-\mathrm{NMR}\left(75 \mathrm{MHz}, \mathrm{CDCl}_{3}\right): \delta=138.5,128.4(2 \mathrm{C}), 127.8(2 \mathrm{C}), 127.7$, 104.6, 79.5, 72.8, 72.7, 59.4, 52.9, 52.6, 33.9, 29.0, 28.2, 25.9 (3C), 18.2, -5.40, -5.42. HRMS (ESI): $\mathrm{m} / \mathrm{z}$ calcd. for $\mathrm{C}_{22} \mathrm{H}_{40} \mathrm{NaO}_{5} \mathrm{Si}\left(\mathrm{M}+\mathrm{Na}^{+}\right): 435.2543$, found: 435.2509 .

A suspension of mineral oil-free potassium hydride $(347 \mathrm{mg}, 8.65 \mathrm{mmol})$ in THF $(10 \mathrm{~mL})$ was cooled to $0{ }^{\circ} \mathrm{C}$ and treated with a solution of the secondary alcohol $(1.55 \mathrm{~g}, 3.76 \mathrm{mmol})$ in THF $(10 \mathrm{~mL})$. After $1 \mathrm{~h}$ at $0{ }^{\circ} \mathrm{C}$ the mixture was cooled to $-78^{\circ} \mathrm{C}$ and trichloroethylene $(395 \mu \mathrm{L}$, $4.14 \mathrm{mmol}$ ) was added dropwise. The solution was allowed to warm up to $\mathrm{rt}$ whereupon it turned dark brown. It was stirred for $1 \mathrm{~h}$ at $\mathrm{rt}$, then again cooled to $-78{ }^{\circ} \mathrm{C}$ and methyllithium $(1.66 \mathrm{M}$ in $\mathrm{Et}_{2} \mathrm{O}, 5.7 \mathrm{~mL}, 9.40 \mathrm{mmol}$ ) was added. After stirring at this temperature for $30 \mathrm{~min}$ it was allowed

\footnotetext{
${ }^{5}$ Landmann, R,; Hoffmann, R. W. Chem. Ber. 1987, 120, 331-333.
} 
to warm up to $-40{ }^{\circ} \mathrm{C}$ over a $30 \mathrm{~min}$ period and was stirred again for $30 \mathrm{~min}$. The reaction was quenched by adding $\mathrm{MeOH}(1.5 \mathrm{~mL}, 38 \mathrm{mmol})$ and warmed to rt. The mixture was diluted with TBME $(50 \mathrm{~mL})$ and subjected to aqueous workup using sat. $\mathrm{NaHCO}_{3}$-solution $(30 \mathrm{~mL})$ and TBME $(3 \times 40 \mathrm{~mL})$. Drying of the combined organic layers with $\mathrm{Na}_{2} \mathrm{SO}_{4}$ and subsequent flash chromatography on basic alumina (pentane/ $\mathrm{Et}_{2} \mathrm{O}$ 6:1) afforded the ynolether 6 (1.176 g, $2.71 \mathrm{mmol}, 72 \%$ ) as a colorless oil that was used immediately for the next transformation. $R_{\mathrm{f}}=0.35$ (pentane/TBME 5:1). $[\alpha]_{\mathrm{D}}=-20.0\left(\mathrm{c}=1.40, \mathrm{CHCl}_{3}, \vartheta=20^{\circ} \mathrm{C}\right) .{ }^{1} \mathrm{H}-\mathrm{NMR}(300 \mathrm{MHz}$, $\left.\mathrm{CDCl}_{3}\right): \delta=7.36-7.25(\mathrm{~m}, 5 \mathrm{H}), 4.67(\mathrm{~d}, J=11.5 \mathrm{~Hz}, 1 \mathrm{H}), 4.59(\mathrm{~d}, J=11.2 \mathrm{~Hz}, 1 \mathrm{H}), 4.37(\mathrm{t}$, $J=5.0 \mathrm{~Hz}, 1 \mathrm{H}), 4.15-4.08(\mathrm{~m}, 1 \mathrm{H}), 3.90(\mathrm{ddd}, J=8.7,5.0,4.0 \mathrm{~Hz}, 1 \mathrm{H}), 3.73(\mathrm{dd}, J=7.1,5.1 \mathrm{~Hz}$, $2 \mathrm{H}), 3.32(\mathrm{~s}, 3 \mathrm{H}), 3.31(\mathrm{~s}, 3 \mathrm{H}), 1.87-1.61(\mathrm{~m}, 6 \mathrm{H}), 1.55(\mathrm{~s}, 1 \mathrm{H}), 0.90(\mathrm{~s}, 9 \mathrm{H}), 0.05(\mathrm{~s}, 6 \mathrm{H}) .{ }^{13} \mathrm{C}-$ NMR (75 MHz, $\mathrm{CDCl}_{3}$ ): $\delta=138.3,128.3$ (2C), 128.0 (2C), 127.7, 104.1, 92.0, 90.5, 75.7, 73.3, 59.0, 53.0, 52.6, 33.1, 28.3, 27.1, 25.9 (3C), 24.5, 18.2, -5.36, -5.41. HRMS (ESI): $\mathrm{m} / \mathrm{z}$ calcd. for $\mathrm{C}_{24} \mathrm{H}_{40} \mathrm{NaO}_{5} \mathrm{Si}\left(\mathrm{M}+\mathrm{Na}^{+}\right)$: 436.2645 , found: 436.2643 .

\section{2-\{(E)-3'-[(1'’S,2'’S)-2'’-Benzyloxy-4’'-(tert-butyl-dimethyl-silanyloxy)-1'”-(dimethoxy-} propyl)-butoxy]-2'-propenyl\}-4,4,5,5-tetramethyl-[1,3,2]-dioxaborolane (7)

A solution of ynolether $6(286 \mathrm{mg}, 0.65 \mathrm{mmol})$ in $\mathrm{CH}_{2} \mathrm{Cl}_{2}(0.32 \mathrm{~mL})$ was treated with pinacolborane (92 mg, $0.72 \mathrm{mmol}$ ) and zirconocene chloride hydride (17 mg, $0.065 \mathrm{mmol})$ and then stirred for $24 \mathrm{~h}$ at $\mathrm{rt}$. Then TBME $(20 \mathrm{~mL})$ was added and the mixture was washed with phosphate-buffer $(2 \mathrm{M}, \mathrm{pH} 7,20 \mathrm{~mL})$. Extraction of the aqueous layer with TBME $(3 \times 20 \mathrm{~mL})$ and drying of the combined organic extracts with $\mathrm{Na}_{2} \mathrm{SO}_{4}$ followed by flash chromatography on silica neutralized with $\mathrm{Et}_{3} \mathrm{~N}$ (pentane/TBME 5:1) afforded the vinylboronate (258 $\mathrm{mg}, 046 \mathrm{mmol}$, $70 \%)$ as a colorless oil. $R_{\mathrm{f}}=0.22$ (pentane/TBME 5:1), ${ }^{1} \mathrm{H}-\mathrm{NMR}\left(300 \mathrm{MHz}, \mathrm{CDCl}_{3}\right): \delta=7.36$ $7.22(\mathrm{~m}, 5 \mathrm{H}), 6.96(\mathrm{~d}, J=14.2 \mathrm{~Hz}, 1 \mathrm{H}), 4.63(\mathrm{~d}, J=11.0 \mathrm{~Hz}, 1 \mathrm{H}), 4.54$ (d, $J=13.9 \mathrm{~Hz}, 1 \mathrm{H}), 4.52$ $(\mathrm{d}, J=11.0 \mathrm{~Hz}, 1 \mathrm{H}), 4.32(\mathrm{t}, J=4.5 \mathrm{~Hz}, 1 \mathrm{H}), 3.99-3.88(\mathrm{~m}, 1 \mathrm{H}), 3.77-3.64(\mathrm{~m}, 3 \mathrm{H}), 3.30(\mathrm{~s}, 3 \mathrm{H})$, $3.29(\mathrm{~s}, 3 \mathrm{H}), 1.82-1.51(\mathrm{~m}, 6 \mathrm{H}), 1.25(\mathrm{~s}, 12 \mathrm{H}), 0.89(\mathrm{~s}, 9 \mathrm{H}), 0.04(\mathrm{~s}, 6 \mathrm{H}) .{ }^{13} \mathrm{C}-\mathrm{NMR}(75 \mathrm{MHz}$, $\left.\mathrm{CDCl}_{3}\right): \delta=163.8,138.5,128.3(2 \mathrm{C}), 128.1$ (2C), 127.6, 104.3, 83.1 (2C), 82.5, 76.9, 73.3, 59.2, $53.0,52.6,33.6,28.5,25.9$ (3C), 25.2, 24.8 (4C), 18.2, -5.3, -5.4, the signal of the C-atom next to the boron was not observed. 
A solution of the vinylboronate $(954 \mathrm{mg}, 1.69 \mathrm{mmol})$ and chloroiodomethane $(160 \mu \mathrm{L}$, $2.20 \mathrm{mmol})$ in THF $(9 \mathrm{~mL})$ was treated dropwise with $n \mathrm{BuLi}(1.64 \mathrm{M}$ in hexane, $1.34 \mathrm{~mL}$, $2.20 \mathrm{~mL}$ ) at $-100^{\circ} \mathrm{C}$. The mixture was allowed to warm up to rt within $8 \mathrm{~h}$ and was stirred at $\mathrm{rt}$ for $4 \mathrm{~h}$. Then it was diluted with TBME $(25 \mathrm{~mL})$ and washed with phosphate-buffer $(2 \mathrm{M}, \mathrm{pH} 7$, $20 \mathrm{~mL})$. The aqueous layer was extracted with TBME $(3 \times 20 \mathrm{~mL})$ and the combined organic extracts were dried with $\mathrm{Na}_{2} \mathrm{SO}_{4}$. The solvent was evaporated to give allylboronate 7 (936 mg, $1.62 \mathrm{mmol}, 96 \%$ ) as a pale yellow oil that due to its sensitivity was used without purification. $R_{\mathrm{f}}=0.21$ (pentane/TBME 5:1). ${ }^{1} \mathrm{H}-\mathrm{NMR}\left(300 \mathrm{MHz}, \mathrm{CDCl}_{3}\right): \delta=7.37-7.22(\mathrm{~m}, 5 \mathrm{H}), 6.08(\mathrm{dt}$, $J=12.5,1.0 \mathrm{~Hz}, 1 \mathrm{H}), 4.92(\mathrm{dt}, J=12.2,7.6 \mathrm{~Hz}, 1 \mathrm{H}), 4.63(\mathrm{~d}, J=11.5 \mathrm{~Hz}, 1 \mathrm{H}), 4.54(\mathrm{~d}$, $J=11.2 \mathrm{~Hz}, 1 \mathrm{H}), 4.33(\mathrm{t}, J=5.3 \mathrm{~Hz}, 1 \mathrm{H}), 3.74-3.61(\mathrm{~m}, 4 \mathrm{H}), 3.30(\mathrm{~s}, 3 \mathrm{H}), 3.29$ (s, 3H), $1.87-$ $1.51(\mathrm{~m}, 6 \mathrm{H}), 1.47\left(\mathrm{~m}_{\mathrm{c}}, 2 \mathrm{H}\right), 1.23(\mathrm{~s}, 12 \mathrm{H}), 0.89(\mathrm{~s}, 9 \mathrm{H}), 0.04(\mathrm{~s}, 6 \mathrm{H}) \cdot{ }^{13} \mathrm{C}-\mathrm{NMR}(75 \mathrm{MHz}$, $\left.\mathrm{CDCl}_{3}\right): \delta=146.4,138.8,128.3$ (2C), 128.1 (2C), 127.5, 104.5, 100.8, 83.1 (2C), 81.6, 76.9, $73.1,59.5,52.8,52.6,33.3,28.6,25.9$ (3C), 25.1, 24.8 (4C), 18.2, -5.3, -5.4 , the signal of the Catom next to the boron was not observed.

\section{$(2 S, 3 R, 6 S)-6-[(S)-1$ '-Benzyloxy-3'-hydroxy-propyl]-2-vinyl-tetrahydropyran-3-ol (9)}

A solution of allylboronate $7(451 \mathrm{mg}, 0.78 \mathrm{mmol})$ in acetonitrile $(8 \mathrm{~mL})$ was treated with ytterbium triflate $(48 \mathrm{mg}, 0.078 \mathrm{mmol})$ and $\mathrm{H}_{2} \mathrm{O}(160 \mu \mathrm{L})$. The solution was stirred at $\mathrm{rt}$ overnight. Then sat. $\mathrm{NaHCO}_{3}$-solution was added and the mixture was stirred for $15 \mathrm{~min}$. Subsequently it was saturated with solid $\mathrm{NaCl}$ and extracted with TBME $(4 \times 20 \mathrm{~mL})$. After evaporation of the solvent in vacuum the residue was purified by flash chromatography on silica neutralized with $\mathrm{Et}_{3} \mathrm{~N}$ (pentane/ $\mathrm{Et}_{2} \mathrm{O} 2: 1$ ) to afford alcohol 9 (179 $\mathrm{mg}, 0.62 \mathrm{mmol}, 79 \%$ ) as a colorless oil. $R_{\mathrm{f}}=0.25$ (TBME). $[\alpha]_{\mathrm{D}}=-49.5\left(\mathrm{c}=1.05, \mathrm{CHCl}_{3}, \vartheta=20^{\circ} \mathrm{C}\right) .{ }^{1} \mathrm{H}-\mathrm{NMR}(300 \mathrm{MHz}$, $\left.\mathrm{CDCl}_{3}\right): \delta=7.40-7.23(\mathrm{~m}, 5 \mathrm{H}), 5.92(\mathrm{ddd}, J=17.3,10.6,6.7 \mathrm{~Hz}, 1 \mathrm{H}), 5.39(\mathrm{~d}, J=17.3 \mathrm{~Hz}, 1 \mathrm{H})$, $5.29(\mathrm{~d}, J=10.5 \mathrm{~Hz}, 1 \mathrm{H}), 4.71(\mathrm{~d}, J=11.5 \mathrm{~Hz}, 1 \mathrm{H}), 4.59$ (d, $J=11.5,1 \mathrm{H}), 3.77-3.62(\mathrm{~m}, 3 \mathrm{H})$, $3.56\left(\mathrm{~m}_{\mathrm{c}}, 2 \mathrm{H}\right), 3.29\left(\mathrm{~m}_{\mathrm{c}}, 1 \mathrm{H}\right), 2.61(\mathrm{bs}, 1 \mathrm{H}), 2.21-2.11(\mathrm{~m}, 2 \mathrm{H}), 1.91-1.68(\mathrm{~m}, 3 \mathrm{H}), 1.51\left(\mathrm{~m}_{\mathrm{c}}, 1 \mathrm{H}\right)$.

${ }^{13} \mathrm{C}-\mathrm{NMR}\left(75 \mathrm{MHz}, \mathrm{CDCl}_{3}\right): \delta=138.2,136.0,128.4$ (2C), 128.0 (2C), 127.7, 118.4, 83.8, 79.3, 78.8, 72.9, 69.4, 60.1, 32.8, 31.5, 25.6. HRMS (EI): $\mathrm{m} / \mathrm{z}$ calcd. for $\mathrm{C}_{17} \mathrm{H}_{24} \mathrm{O}_{4}\left(\mathrm{M}^{+}\right)$: 292.1675, found: 292.1673 . 

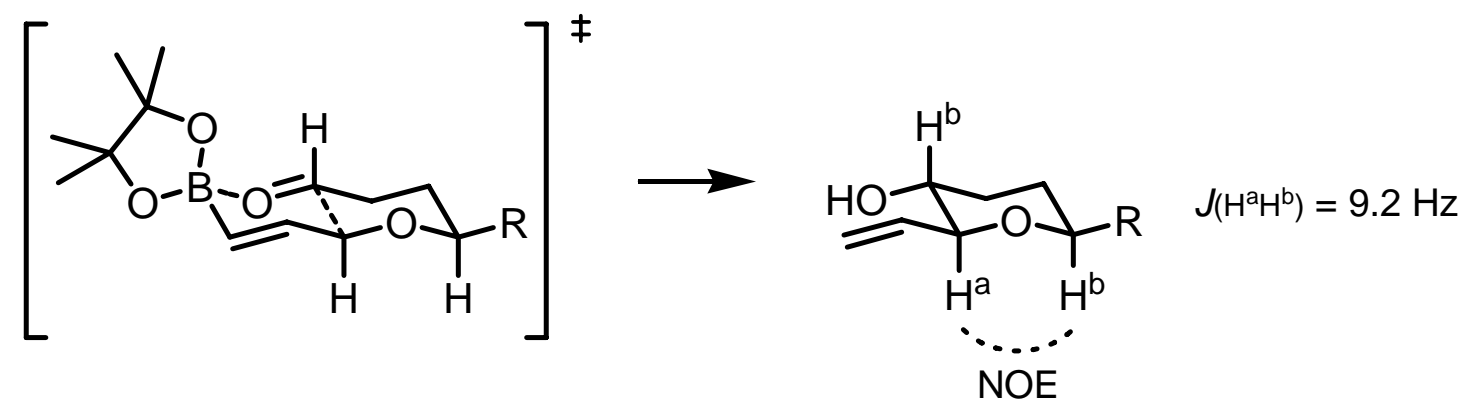

The relative configuration of $\mathbf{9}$ was determined by NMR-correlation spectra. The coupling constant of $9.2 \mathrm{~Hz}$ between $\mathrm{H}^{\mathrm{a}}$ and $\mathrm{H}^{\mathrm{b}}$ indicates a trans-equatorial arragement of the vinyl- and the hydroxy-group. Furthermore an NOE-contact between $\mathrm{H}^{\mathrm{a}}$ and $\mathrm{H}^{\mathrm{c}}$ that implies their 1,3-diaxial location was observed.

\section{(2S,3R,6S)-6-[(1’S)-1'-Benzyloxy-3'-tert-butyl-dimethylsilyloxy]-2-(Z)-dec-3'’-enyl-3-tert- butyl-dimethylsilyloxy-tetrahydropyrane (10)}

A solution of diol 9 ( $46 \mathrm{mg}, 0.16 \mathrm{mmol})$ in dichloromethane $(0.4 \mathrm{~mL})$ was cooled to $-20{ }^{\circ} \mathrm{C}$ and after addition of 2,6-lutidine $(91 \mu \mathrm{L}, 0.79 \mathrm{mmol})$ treated with tert-butyl-dimethylsilyl triflate $(109 \mu \mathrm{L}, 0.47 \mathrm{mmol})$. The mixture was warmed to $-10{ }^{\circ} \mathrm{C}$ within $30 \mathrm{~min}$ and quenched by addition of methanol $(20 \mu \mathrm{L})$. Aqueous workup using sat. $\mathrm{NaHCO}_{3}$-solution $(10 \mathrm{~mL})$ and extraction with TBME $(3 \times 15 \mathrm{~mL})$ followed by flash chromatography on silica gel (pentane/TBME 20:1) afforded the desired di-TBS ether ( $75 \mathrm{mg}, 0.15 \mathrm{mmol}, 92 \%)$ as a colorless oil. $R_{\mathrm{f}}=0.59$ (pentane/TBME 10:1). $[\alpha]_{\mathrm{D}}=-49.4\left(\mathrm{c}=1.46, \mathrm{CHCl}_{3}, \vartheta=20^{\circ} \mathrm{C}\right) .{ }^{1} \mathrm{H}-\mathrm{NMR}$ $\left(300 \mathrm{MHz}, \mathrm{CDCl}_{3}\right): \delta=7.38-7.23(\mathrm{~m}, 5 \mathrm{H}), 5.98(\mathrm{ddd}, J=17.3,10.7,5.4 \mathrm{~Hz}, 1 \mathrm{H}), 5.33$ (ddd, $J=17.3,1.9,1.5 \mathrm{~Hz}, 1 \mathrm{H}), 5.15(\mathrm{ddd}, J=10.7,1.9,1.2 \mathrm{~Hz}, 1 \mathrm{H}), 4.73(\mathrm{~d}, J=11.5 \mathrm{~Hz}, 1 \mathrm{H}), 4.57$ (d, $J=11.5 \mathrm{~Hz}, 1 \mathrm{H}), 3.77-3.68(\mathrm{~m}, 2 \mathrm{H}), 3.66-3.55(\mathrm{~m}, 2 \mathrm{H}), 3.54-3.47(\mathrm{~m}, 1 \mathrm{H}), 3.35-3.25(\mathrm{~m}$, 1H), 2.10-2.00 (m, 1H), 1.82 (dddd, $J=14.0,7.2,7.0,4.0 \mathrm{~Hz}, 1 \mathrm{H}) 1.74-1.61(\mathrm{~m}, 2 \mathrm{H}), 1.59-1.42$ (m, 2H), 0.90 (s, 9H), 0.88 (s, 9H), 0.05 (s, 3H), 0.044 (s, 6H), 0.037 (s, 3H). ${ }^{13} \mathrm{C}-\mathrm{NMR}(75 \mathrm{MHz}$, $\left.\mathrm{CDCl}_{3}\right): \delta=139.0,136.9,128.2(2 \mathrm{C}), 128.0(2 \mathrm{C}), 127.5,115.7,82.3,79.1,77.8,73.2,71.4,59.8$, 33.8, 33.5, 26.1, 26.0 (3C), 25.8 (3C), 18.3, 18.0, -4.2, -4.6, -5.30, -5.32. HRMS (ESI): $\mathrm{m} / \mathrm{z}$ calcd. for $\mathrm{C}_{29} \mathrm{H}_{52} \mathrm{NaO}_{4} \mathrm{Si}_{2}\left(\mathrm{M}+\mathrm{Na}^{+}\right)$: 543.3296 , found: 543.3296 . 
To a solution of the di-TBS ether $(110 \mathrm{mg}, 0.21 \mathrm{mmol})$ in THF $(2.1 \mathrm{~mL})$ was added $\mathrm{Rh}(\mathrm{CO})_{2}(\mathrm{acac})(1 \mathrm{mg}, 4.2 \mu \mathrm{mol})$ and BIPHEPHOS $(13.4 \mathrm{mg}, 17 \mu \mathrm{mol})$. The resulting solution was transferred into a steel autoclave which was flushed with $\mathrm{CO} / \mathrm{H}_{2}(1: 1)$, pressurized (approx. 8 bar) and heated to $50^{\circ} \mathrm{C}$ for $36 \mathrm{~h}$. After cooling to $\mathrm{rt}$ the reaction mixture was diluted with TBME $(20 \mathrm{~mL})$, transferred to a glass flask, concentrated and the crude aldehyde was used immediately for the next step without purification.

Heptyl-triphenylphosphonium bromide (185 mg, $0.42 \mathrm{mmol})$ was dissolved in THF (1 mL), cooled to $0{ }^{\circ} \mathrm{C}$ and treated with NaHMDS ( $2 \mathrm{M}$ in THF, $0.21 \mathrm{~mL}, 0.42 \mathrm{mmol}$ ). The mixture was warmed to rt, and after $30 \mathrm{~min}$ cooled to $-78^{\circ} \mathrm{C}$. The crude aldehyde in THF $(1.1 \mathrm{~mL})$ was added and the mixture stirred at $-78^{\circ} \mathrm{C}$ for $1 \mathrm{~h}$ and at $\mathrm{rt}$ for $2.5 \mathrm{~h}$. After dilution with TBME $(20 \mathrm{~mL})$, aqueous workup using sat. $\mathrm{NaHCO}_{3}$-solution $(20 \mathrm{~mL})$, extraction with TBME $(3 \times 20 \mathrm{~mL})$, and flash chromatography on silica gel (pentane/TBME 20:1) the desired olefin 10 (125 mg, $0.20 \mathrm{mmol}, 94 \%$, both steps) was obtained as a colorless oil. $R_{\mathrm{f}}=0.65$ (pentane/TBME 10:1). $[\alpha]_{\mathrm{D}}=-43.0\left(\mathrm{c}=1.19, \mathrm{CHCl}_{3}, \vartheta=20^{\circ} \mathrm{C}\right) .{ }^{1} \mathrm{H}-\mathrm{NMR}\left(300 \mathrm{MHz}, \mathrm{CDCl}_{3}\right): \delta=7.37-7.23(\mathrm{~m}, 5 \mathrm{H})$, 5.43-5.28 (m, 2H), $4.74(\mathrm{~d}, J=11.5 \mathrm{~Hz}, 1 \mathrm{H}), 4.58$ (d, $J=11.5 \mathrm{~Hz}, 1 \mathrm{H}), 3.78-3.64(\mathrm{~m}, 2 \mathrm{H}), 3.61-$ $3.52(\mathrm{~m}, 1 \mathrm{H}), 3.44-3.35(\mathrm{~m}, 1 \mathrm{H}), 3.33-3.21(\mathrm{~m}, 1 \mathrm{H}), 3.05(\mathrm{td}, J=9.1,2.0,1 \mathrm{H}), 2.33-2.05(\mathrm{~m}$, 2H), 2.04-1.94 (m, 3H) 1.89-1.36 (m, 7H), 1.35-1.20 (m, 8H), 0.89 (s, 9H), 0.88 (s, 9H), 0.87 (t, $J=7.0 \mathrm{~Hz}, 3 \mathrm{H}), 0.06$ (s, 6H), 0.04 (s, 6H). ${ }^{13} \mathrm{C}-\mathrm{NMR}\left(75 \mathrm{MHz}, \mathrm{CDCl}_{3}\right): \delta=139.1,130.2,129.6$, 128.2 (2C), 128.0 (2C), 127.4, 82.1, 79.6, 78.0, 73.3, 71.4, 59.7, 33.9, 33.5, 32.3, 31.8, 29.8, 29.0, 27.3, 26.7, 26.0 (3C), 25.8 (3C), 23.4, 22.6, 18.3, 18.0, 14.1, -4.0, -4.7, -5.30, -5.31. HRMS (ESI): $m / z$ calcd. for $\mathrm{C}_{37} \mathrm{H}_{68} \mathrm{NaO}_{4} \mathrm{Si}_{2}\left(\mathrm{M}+\mathrm{Na}^{+}\right)$: 655.4544 , found: 655.4548 .

\section{(2S,3R,6S)-6-[(1’S)-1'-Benzyloxy-3'-iodo-propyl]-2-(Z)-dec-3'’-enyl-3-tert-butyldimethyl- silyloxy-tetrahydropyrane (11)}

A solution of $10(94 \mathrm{mg}, 0.15 \mathrm{mmol})$ in dichloromethane $(1.0 \mathrm{~mL})$ was treated with CSA (3.5 mg, $15 \mu \mathrm{mol})$ dissolved in methanol $(0.5 \mathrm{~mL})$ at $\mathrm{rt}$. Stirring was continued for $1 \mathrm{~h}$. After addition of sat. $\mathrm{NaHCO}_{3}$-solution $(10 \mathrm{~mL})$ and extraction with TBME $(3 \times 15 \mathrm{~mL})$, flash chromatography on silica gel (pentane/TBME 2:1) furnished the primary alcohol (66 mg, $0.13 \mathrm{mmol}, 86 \%$ ) as a colorless oil. $R_{\mathrm{f}}=0.11$ (pentane/TBME 5:1). $[\alpha]_{\mathrm{D}}=-56.7(\mathrm{c}=1.98$, 
$\left.\mathrm{CHCl}_{3}, \vartheta=20^{\circ} \mathrm{C}\right) .{ }^{1} \mathrm{H}-\mathrm{NMR}\left(300 \mathrm{MHz}, \mathrm{CDCl}_{3}\right): \delta=7.37-7.24(\mathrm{~m}, 5 \mathrm{H}), 5.43-5.29(\mathrm{~m}, 2 \mathrm{H}), 4.77$ $(\mathrm{d}, J=11.5 \mathrm{~Hz}, 1 \mathrm{H}), 4.60(\mathrm{~d}, J=11.5 \mathrm{~Hz}, 1 \mathrm{H}), 3.77-3.67$ (m, 2H), 3.66-3.57 (m, 1H), 3.54-3.43 (m, 1H), 3.32-3.22 (m, 1H), 3.15-3.04 (m, 1H), 2.40 (bs, 2H), 2.30-2.07 (m, 2H), 2.06-1.94 (m, $3 \mathrm{H}) 1.92-1.72(\mathrm{~m}, 3 \mathrm{H}), 1.70-1.59(\mathrm{~m}, 1 \mathrm{H}), 1.54-1.36(\mathrm{~m}, 3 \mathrm{H}), 1.34-1.21(\mathrm{~m}, 8 \mathrm{H}), 0.88(\mathrm{~s}, 9 \mathrm{H})$, $0.87(\mathrm{t}, J=7.0 \mathrm{~Hz}, 3 \mathrm{H}), 0.06(\mathrm{~s}, 6 \mathrm{H}) .{ }^{13} \mathrm{C}-\mathrm{NMR}\left(75 \mathrm{MHz}, \mathrm{CDCl}_{3}\right): \delta=140.0,130.3,129.4,128.4$ (2C), 128.0 (2C), 127.8, 82.1, 80.0, 79.4, 73.2, 71.1, 60.5, 33.3, 33.0, 32.2, 31.8, 29.8, 29.0, 27.2, 27.0, 25.8 (3C), 23.3, 22.6, 18.0, 14.1, -4.0, -4.7. HRMS (ESI): $\mathrm{m} / \mathrm{z}$ calcd. for $\mathrm{C}_{31} \mathrm{H}_{54} \mathrm{NaO}_{4} \mathrm{Si}$ $\left(\mathrm{M}+\mathrm{Na}^{+}\right): 541.3679$, found: 541.3684 .

The primary alcohol (202 mg, $0.39 \mathrm{mmol})$ and pyridine $(135 \mu \mathrm{L}, 1.62 \mathrm{mmol})$ were dissolved in $\mathrm{CH}_{2} \mathrm{Cl}_{2}(3 \mathrm{~mL})$, cooled to $0^{\circ} \mathrm{C}$ and treated with $\mathrm{TsCl}(156 \mathrm{mg}, 0.82 \mathrm{mmol})$ and DMAP $(5 \mathrm{mg}$, $0.04 \mathrm{mmol})$. After stirring at $\mathrm{rt}$ overnight additional pyridine $(65 \mu \mathrm{L}, 0.78 \mathrm{mmol})$ and $\mathrm{TsCl}$ (74 mg, $0.39 \mathrm{mmol})$ were added. After $3 \mathrm{~h}$ at $\mathrm{rt}$ phosphate-buffer $(2 \mathrm{M}, \mathrm{pH} 7,2 \mathrm{~mL})$ was added and the layers were separated. The aqueous layer was extracted with TBME $(3 \times 5 \mathrm{~mL})$ and the combined organic layers were washed with sat. $\mathrm{NaCl}$-solution $(3 \mathrm{~mL})$ and dried with $\mathrm{Na}_{2} \mathrm{SO}_{4}$. Flash chromatography on silica (20 g, pentane/TBME 10:1) afforded the tosylate (276 mg, $0.37 \mathrm{mmol}, 95 \%)$ as a colorless oil. $R_{\mathrm{f}}=0.31$ (pentane/TBME 7:1). $[\alpha]_{\mathrm{D}}=-41.2(\mathrm{c}=1.07$, $\left.\mathrm{CHCl}_{3}, \vartheta=19^{\circ} \mathrm{C}\right) .{ }^{1} \mathrm{H}-\mathrm{NMR}\left(300 \mathrm{MHz}, \mathrm{CDCl}_{3}\right): \delta=7.77(\mathrm{pd}, J=8.3 \mathrm{~Hz}, 2 \mathrm{H}), 7.30-7.21(\mathrm{~m}$, 5H), 7.20-7.15 (m, 2H), 5.36-5.22 (m, 2H), 4.66 (d, J=11.3 Hz, 1H), 4.39 (d, J=11.3 Hz, 1H), 4.16-4.00 (m, 2H), 3.43 (ddd, $J=9.1,4.7,4.5 \mathrm{~Hz}, 1 \mathrm{H}), 3.29-3.13$ (m, 2H), 2.93 (ddd, $J=9.0,9.0$, $2.1 \mathrm{~Hz}, 1 \mathrm{H}), 2.42$ (s, 3H), 2.20-2.06 (m, 1H), 2.06-1.98 (m, 1H), 1.97-1.83 (m, 4H), 1.82-1.69 $(\mathrm{m}, 2 \mathrm{H}), 1.51-1.16(\mathrm{~m}, 12 \mathrm{H}), 0.87(\mathrm{~s}, 9 \mathrm{H}), 0.86-0.79(\mathrm{~m}, 3 \mathrm{H}), 0.04(\mathrm{~s}, 6 \mathrm{H}) .{ }^{13} \mathrm{C}-\mathrm{NMR}(75 \mathrm{MHz}$, $\left.\mathrm{CDCl}_{3}\right): \delta=144.7,138.4,133.1,130.3,130.2,129.8$ (2C), 129.4, 128.3 (2C), 127.93 (2C), 127.91 (2C), 127.6, 127.1, 82.1, 79.1, 73.4, 71.1, 67.7, 33.3, 32.2, 31.8, 30.3, 29.8, 29.0, 27.3, $26.4,25.8$ (3C), 23.3, 22.6, 21.6, 18.0, 14.1, -4.0,-4.7.

The tosylate $(238 \mathrm{mg}, 0.354 \mathrm{mmol})$ and $\mathrm{NaI}(265 \mathrm{mg}, 1.768 \mathrm{mmol})$ were dissolved in acetone $(5 \mathrm{~mL})$ and stirred at $\mathrm{rt}$ for $16 \mathrm{~h}$ under light exclusion. After further addition of $\mathrm{NaI}(106 \mathrm{mg}$, $0.707 \mathrm{mmol}$ ) the suspension was stirred at $50^{\circ} \mathrm{C}$ for $5 \mathrm{~h}$. The acetone was evaporated in vacuum and the residue was redissolved in TBME $(25 \mathrm{~mL})$, washed with half-sat. $\mathrm{Na}_{2} \mathrm{~S}_{2} \mathrm{O}_{3}$-solution $(5 \mathrm{~mL})$, half-sat. $\mathrm{NaHCO}_{3}$-solution $(5 \mathrm{~mL})$ and sat. $\mathrm{NaCl}$-solution and dried with $\mathrm{Na}_{2} \mathrm{SO}_{4}$. Purification by flash chromatography on neutral silica $(20 \mathrm{~g}$, pentane/TBME 15:1 $\rightarrow$ 10:1) 
afforded iodide 11 (202 mg, $0.321 \mathrm{mmol}, 91 \%$ ) as a colorless oil that was stored at $-18{ }^{\circ} \mathrm{C}$ under exclusion of light. $R_{\mathrm{f}}=0.56$ (cyclohexane/TBME 10:1). $[\alpha]_{\mathrm{D}}=-59.6 \quad\left(\mathrm{c}=1.06, \mathrm{CHCl}_{3}\right.$, $\left.\vartheta=20^{\circ} \mathrm{C}\right) .{ }^{1} \mathrm{H}-\mathrm{NMR}\left(300 \mathrm{MHz}, \mathrm{CDCl}_{3}\right): \delta=7.42-7.26(\mathrm{~m}, 5 \mathrm{H}), 5.43-5.30(\mathrm{~m}, 2 \mathrm{H}), 4.78(\mathrm{~d}$, $J=11.3,1 \mathrm{H}), 4.60(\mathrm{~d}, J=11.3,1 \mathrm{H}), 3.53(\mathrm{ddd}, J=8.4,4.7,4.7 \mathrm{~Hz}, 1 \mathrm{H}), 3.48-3.37(\mathrm{~m}, 1 \mathrm{H})$, 3.34-3.19 (m, 3H), 3.06 (ddd, $J=9.1,9.1,2.2 \mathrm{~Hz}, 1 \mathrm{H}), 2.30-2.17$ (m, 1H), 2.16-1.92 (m, 6H), 1.91-1.77 (m, 1H), 1.66-1.55 (m, 1H), 1.53-1.36 (m, 3H), 1.35-1.20 (m, 8H), 0.91-0.86 (m, 3H), $0.88(\mathrm{~s}, 9 \mathrm{H}), 0.06(\mathrm{~s}, 6 \mathrm{H}) .{ }^{13} \mathrm{C}-\mathrm{NMR}\left(75 \mathrm{MHz}, \mathrm{CDCl}_{3}\right): \delta=138.6,130.3,129.5,128.4(2 \mathrm{C})$, 128.1 (2C), 127.7, 82.2, 80.7, 78.9, 73.7, 71.2, 34.9, 33.4, 32.3, 31.8, 29.8, 29.0, 27.3, 26.4, 25.8 (3C), 23.4, 22.6, 18.0, 14.1, 3.4, -4.0, -4.7. IR (Film): 2954 (s), 2927 (s), 2856 (s), 1455 (w), 1251 (w), 1095 (s), 837 (m), 775 (m), 696 (w), 671 (w). HRMS (ESI): m/z calcd. for $\mathrm{C}_{31} \mathrm{H}_{53} \mathrm{NaO}_{3} \mathrm{Si}\left(\mathrm{M}+\mathrm{Na}^{+}\right)$: 651.2701, found: 651.2714 .

\section{(2R)-1-O-Triethylsilyloxy-2-tert-butyl-dimethylsilyloxy-10-benzyloxy-decane (14)}

Mg-turnings ( $0.72 \mathrm{~g}, 29.4 \mathrm{mmol})$ were heated in vacuum, stirred for $0.5 \mathrm{~h}$ in an argon atmosphere and suspended in THF $(10 \mathrm{~mL})$. The bromide $(7.00 \mathrm{~g}, 24.5 \mathrm{mmol})$ was dissolved in THF $(20 \mathrm{~mL})$ and at first 1/5 of the bromide solution was added to the Mg-suspension. The mixture was mildly heated and as soon as the reaction started the remaining bromide-solution was added dropwise. After $30 \mathrm{~min}$ reflux the resulting grey suspension was cooled to $-30{ }^{\circ} \mathrm{C}$ and $\mathrm{CuI}(560 \mathrm{mg}$, $2.94 \mathrm{mmol}$ ) was added. Subsequently TES-glycidole (3.69 g, $19.6 \mathrm{mmol})$ was added dropwise within $15 \mathrm{~min}$. The reaction mixture was warmed to $0{ }^{\circ} \mathrm{C}$ over a $2-3 \mathrm{~h}$ period. The reaction was quenched by the addition of a half-saturated $\mathrm{NH}_{4} \mathrm{Cl}$-solution $(15 \mathrm{~mL})$. After addition of $\mathrm{H}_{2} \mathrm{O}$ $(30 \mathrm{~mL})$ and TBME $(150 \mathrm{~mL})$ the layers were separated and the aqueous layer was extracted with additional TBME $(4 \times 50 \mathrm{~mL})$. The combined organic layers were dried with $\mathrm{Na}_{2} \mathrm{SO}_{4}$, the solvent was evaporated in vacuum and the crude residue was purified by flash chromatography on silica (300 g, pentane-TBME 8:1) to give the secondary alcolol (5.96 g, $15.1 \mathrm{mmol}, 77 \%$ ) as a colorless oil. The yield was increased to $91 \%$ by using 2.5 equiv. of the bromide and 3.0 equiv. $\mathrm{Mg}$ turnings. $\quad R_{\mathrm{f}}=0.11$ (cyclohexane/TBME 10:1), 0.33 (cyclohexane/TBME 5:1). $[\alpha]_{\mathrm{D}}=-2.9$ $\left(\mathrm{c}=2.01, \mathrm{CHCl}_{3}, \vartheta=26^{\circ} \mathrm{C}\right) .{ }^{1} \mathrm{H}-\mathrm{NMR}\left(300 \mathrm{MHz}, \mathrm{CDCl}_{3}\right): \delta=7.35-7.27(\mathrm{~m}, 5 \mathrm{H}), 4.50(\mathrm{~s}, 2 \mathrm{H})$, 3.63-3.59 (m, 2H), $3.46(\mathrm{t}, J=6.6 \mathrm{~Hz}, 2 \mathrm{H}),(\mathrm{dd}, J=10.4,8.4 \mathrm{~Hz}, 1 \mathrm{H}), 2.46(\mathrm{~d}, J=3.0 \mathrm{~Hz}, 1 \mathrm{H})$, 
$1.69-1.52(\mathrm{~m}, 2 \mathrm{H}), 1.49-1.22(\mathrm{~m}, 12 \mathrm{H}), 0.96(\mathrm{t}, J=7.5 \mathrm{~Hz}, 9 \mathrm{H}), 0.61(\mathrm{q}, J=7.5 \mathrm{~Hz}, 6 \mathrm{H}),{ }^{13} \mathrm{H}-$ NMR (75 MHz, $\left.\mathrm{CDCl}_{3}\right): \delta=138.7,128.3$ (2C), 127.6 (2C), 127.4, 72.8, 71.8, 70.5, 66.9, 32.7, 29.7, 29.6, 29.5, 29.4, 26.1, 25.5, 6.7 (3C), 4.3 (3C). IR (film): 3571 (br w), 3005 (m), 2934 (s), 2871 (s), 2870 (s), 1496 (w), 1457 (m), 1414 (w), 1365 (w), 1239 (w), 1098 (s), 1006 (m), 909 (s), 723 (s), 699 (w). Analysis: calcd. for $\mathrm{C}_{23} \mathrm{H}_{42} \mathrm{O}_{3} \mathrm{Si}$ : C 70.00, H 10.73; found: C 70.13, H 10.80.

A solution of the alcohol $(4.00 \mathrm{~g}, 10.1 \mathrm{mmol})$ in $\mathrm{CH}_{2} \mathrm{Cl}_{2}(30 \mathrm{~mL})$ was cooled to $-50{ }^{\circ} \mathrm{C}$ and treated with 2,6-lutidine $(3.30 \mathrm{~mL}, 28.4 \mathrm{mmol})$ and TBSOTf $(3.26 \mathrm{~mL}, 14.2 \mathrm{mmol})$. After $2.5 \mathrm{~h}$ at $-50{ }^{\circ} \mathrm{C}$ sat. $\mathrm{NaHCO}_{3}$-solution was added and the mixture was warmed to rt. After phase separation the aqueous layer was extracted with PE $(3 \times 40 \mathrm{~mL})$ and the combined organic extracts were washed with citric acid $\left(5 \%\right.$ in $\left.\mathrm{H}_{2} \mathrm{O}\right)$, sat. $\mathrm{NaHCO}_{3}$-solution and sat. NaCl-solution. Purification by flash chromatography on silica (30 g, PE/MTBE 25:1) gave the TBS-ether 14 $(4.84 \mathrm{~g}, 9.5 \mathrm{mmol}, 94 \%)$ as a colorless oil. $R_{\mathrm{f}}=0.60$ (cyclohexane/TBME 7:1). $[\alpha]_{\mathrm{D}}=+9.0$ $\left(\mathrm{c}=1.00, \mathrm{CHCl}_{3}, \vartheta=21^{\circ} \mathrm{C}\right) .{ }^{1} \mathrm{H}-\mathrm{NMR}\left(300 \mathrm{MHz}, \mathrm{CDCl}_{3}\right): \delta=7.37-7.24(\mathrm{~m}, 5 \mathrm{H}), 4.49(\mathrm{~s}, 2 \mathrm{H})$, 3.69-3.58 (m, 1H), 3.52-3.33 (m, 4H), 1.66-1.45 (m, 3H), 1.43-1.19 (m, 11H), $0.94(\mathrm{t}, J=7.9 \mathrm{~Hz}$, 9H), 0.87 (s, 9H), 0.58 (q, $J=7.8 \mathrm{~Hz}, 6 \mathrm{H}), 0.04$ (s, 6H). ${ }^{13} \mathrm{C}-\mathrm{NMR}\left(75 \mathrm{MHz}, \mathrm{CDCl}_{3}\right): \delta=138.7$, 128.3 (2C), $127.6(2 \mathrm{C}), 127.4,73.3,72.8,70.5,67.1,34.4,29.8,29.5,29.4,26.2,25.9$ (3C), 25.2, 18.2, 6.8 (3C), 4.3 (3C), -4.2, -4.8. IR (Film): 2931 (s), 2857 (s), 2871 (s), 1460 (m), 1410 (m), 1250 (m), 1109 (m), 1006 (w), 836 (m), 805 (m), 775 (m), 732 (m), 697 (w). Analysis: calcd. for $\mathrm{C}_{29} \mathrm{H}_{56} \mathrm{O}_{3} \mathrm{Si}_{2}$ : C 68.44, H 11.09; found: C 68.32, H 10.89.

\section{(2R)-2-tert-Butyl-dimethylsilyloxy-10-benzyloxy-decan-1-al (15)}

To a solution of the TES-ether $14(1.20 \mathrm{~g}, 2.36 \mathrm{mmol})$ in $\mathrm{CH}_{2} \mathrm{Cl}_{2}(20 \mathrm{~mL}) \mathrm{CSA}$ (55 mg, $0.236 \mathrm{mmol})$ dissolved in $\mathrm{MeOH}(10 \mathrm{~mL})$ was added dropwise at $0{ }^{\circ} \mathrm{C}$. After $30 \mathrm{~min}$ stirring at $\mathrm{rt}$ a saturated $\mathrm{NaHCO}_{3}$-solution $\left(30 \mathrm{~mL}\right.$ ) and $\mathrm{H}_{2} \mathrm{O}$ (as much as needed to dissolve the precipitate) was added. The layers were separated and the aqueous layer was extracted with TBME $(3 \times 50 \mathrm{~mL})$. The combined organic extracts were washed with saturated NaCl-solution, dried with $\mathrm{Na}_{2} \mathrm{SO}_{4}$ and the solvent was evaporated in vacuum. The residue was purified by flash chromatoghraphy on neutral silica (100 g, pentane/TBME 10:1) and the alcohol (614 mg, $1.56 \mathrm{mmol}, 66 \%$ ) was afforded as a colorless oil. $R_{\mathrm{f}}=0.43$ (cyclohexane/TBME $\left.3: 1\right) .[\alpha]_{\mathrm{D}}=-7.4$ 
$\left(\mathrm{c}=1.17, \mathrm{CHCl}_{3}, \vartheta=20^{\circ} \mathrm{C}\right) .{ }^{1} \mathrm{H}-\mathrm{NMR}\left(300 \mathrm{MHz}, \mathrm{CDCl}_{3}\right): \delta=7.29-7.17(\mathrm{~m}, 5 \mathrm{H}), 4.43(\mathrm{~s}, 2 \mathrm{H})$, 3.70-3.60 (m, 1H), 3.49 (ddd, $J=10.9,6.3,3.6 \mathrm{~Hz}, 1 \mathrm{H}), 3.42-3.31$ (m, 1H), 3.39 (t, $J=6.7 \mathrm{~Hz}$, 2H), $1.83(\mathrm{t}, J=6.1 \mathrm{~Hz}, 1 \mathrm{H}),$,1.54 (quin, $J=6.6 \mathrm{~Hz}, 2 \mathrm{H}), 1.46-1.35$ (m, 2H), 1.35-1.21 (m, $10 \mathrm{H}), 0.83(\mathrm{~s}, 9 \mathrm{H}), 0.01(\mathrm{~s}, 6 \mathrm{H}) .{ }^{13} \mathrm{C}-\mathrm{NMR}\left(75 \mathrm{MHz}, \mathrm{CDCl}_{3}\right): \delta=138.7,128.3$ (2C), $127.6(2 \mathrm{C})$, 127.4, 72.9, 72.8, 70.5, 66.3, 34.0, 29.8, 29.7, 29.5, 29.4, 25.8 (3C), 25.3, 18.1, -4.4, -4.6. IR (film): 3448 (br m), 2930 (s), 2856 (s), 1463 (m), 1361 (m), 1254 (m), 1206 (w), 1101 (s), 1005 (m), 836 (s), $776(\mathrm{~m}), 735$ (m), 697 (m). HRMS (ESI): m/z calcd. for $\mathrm{C}_{23} \mathrm{H}_{42} \mathrm{NaO}_{3} \mathrm{Si}\left(\mathrm{M}+\mathrm{Na}^{+}\right)$: 417.2795, found: 417.2782 .

A solution of the alcohol $(580 \mathrm{mg}, 1.47 \mathrm{mmol})$ in $\mathrm{CH}_{2} \mathrm{Cl}_{2}(10 \mathrm{~mL})$ was cooled to $0^{\circ} \mathrm{C}$ After addition of pyridine $(0.29 \mathrm{~mL}, 3.53 \mathrm{mmol})$ and DMP $(748 \mathrm{mg}, 1.76 \mathrm{mmol})$ the solution was allowed to reach rt and after $2 \mathrm{~h}$ sat. $\mathrm{NaHCO}_{3}$-solution $(30 \mathrm{~mL})$ and solid $\mathrm{Na}_{2} \mathrm{~S}_{2} \mathrm{O}_{3}(1.65 \mathrm{~g})$ were added. The mixture was stirred for $30 \mathrm{~min}$ and after phase separation the aqueous phase was extracted with TBME $(3 \times 60 \mathrm{~mL})$. The combined organic layers were washed with sat. NaClsolution and dried with $\mathrm{Na}_{2} \mathrm{SO}_{4}$. Purification by flash chromatography on neutal silica (50 g, pentane/TBME 8:1) furnished aldehyde 15 as a colorless oil (490 mg, $1.25 \mathrm{mmol}$, 85\%). $[\alpha]_{\mathrm{D}}=+20.2\left(\mathrm{c}=1.03, \mathrm{CHCl}_{3}, \vartheta=23{ }^{\circ} \mathrm{C}\right) .{ }^{1} \mathrm{H}-\mathrm{NMR}\left(300 \mathrm{MHz}, \mathrm{CDCl}_{3}\right): \delta=9.59(\mathrm{~d}, J=1.7 \mathrm{~Hz}$, 1H), 7.39-7.28 (m, 5H), $4.50(\mathrm{~s}, 2 \mathrm{H}), 3.95(\mathrm{ddd}, J=7.2,5.5,1.7 \mathrm{~Hz}, 1 \mathrm{H}), 3.46(\mathrm{t}, J=6.6 \mathrm{~Hz}$, 2H), 1.68-1.56 (m, 4H), 1.43-1.24 (m, 10H), $0.92(\mathrm{~s}, 9 \mathrm{H}), 0.08(\mathrm{~s}, 3 \mathrm{H}), 0.07$ (s, 3H). ${ }^{13} \mathrm{C}-\mathrm{NMR}$ $\left(75 \mathrm{MHz}, \mathrm{CDCl}_{3}\right): \delta=204.3,138.8,128.3$ (2C), 127.6 (2C), 127.4, 77.7, 72.9, 70.5, 32.6, 29.8, 29.39, 29.36 (2C), 26.2, 25.8 (3C), 24.6, 18.2, -4.6, -4.9. IR (film): 2930 (s), 2656 (m), 1737 (s), 1463 (w), 1361 (w), 1254 (m), 1103 (s), 838 (s), 779 (m), 735 (m), 697 (m). HRMS (ESI): m/z calcd. for $\mathrm{C}_{23} \mathrm{H}_{40} \mathrm{NaO}_{3} \mathrm{Si}\left(\mathrm{M}+\mathrm{Na}^{+}\right)$: 415.2639, found: 440.2633.

\section{(2S,3R,6S)-6-[(1'S,4'S,5'R)-1',13'-Dibenzyloxy-4'-hydroxy-5'-tert-butyldimethylsilyloxy- tridecanyl]-2-(Z)-dec-3’'-enyl-3-tert-butyl-dimethylsilyloxy-tetrahydropyrane (16)}

At $-100{ }^{\circ} \mathrm{C}$ a solution of the iodide $11(120 \mathrm{mg}, 191 \mu \mathrm{mol})$ dissolved in $\mathrm{Et}_{2} \mathrm{O}(2 \mathrm{~mL})$ was treated dropwise with $t \mathrm{BuLi}(1.6 \mathrm{M}$ in pentane, $216 \mu \mathrm{L}, 350 \mu \mathrm{mol})$. The mixture was warmed to $-78^{\circ} \mathrm{C}$ within $30 \mathrm{~min}$, then a solution of aldehyde $15(61 \mathrm{mg}, 156 \mu \mathrm{mol})$ in $\mathrm{Et}_{2} \mathrm{O}(1 \mathrm{~mL})$ was added slowly. The mixture was allowed to reach $-20{ }^{\circ} \mathrm{C}$ within $3 \mathrm{~h}$ and was then quenched by addition 
of phosphate-buffer $(2 \mathrm{M}, \mathrm{pH} 7,1 \mathrm{~mL}), \mathrm{H}_{2} \mathrm{O}(2 \mathrm{~mL})$ and TBME $(5 \mathrm{~mL})$. Aqueous workup using TBME $(3 \times 5 \mathrm{~mL})$ and sat. NaCl-solution, drying with $\mathrm{MgSO}_{4}$ followed by flash chromatography on silica $(10 \mathrm{~g}$, pentane/TBME 20:1 $\rightarrow$ 10:1) to separate the diastereomers afforded alcohol 16 (74 mg, $83 \mu \mathrm{mol}, 53 \%$ ) and the diastereomeric alcohol 16a (29 mg, $33 \mu \mathrm{mol}, 21 \%$ ) as colorless oils. The selectivity was determined by NMR. The relative stereochemistry was assigned using the Hoffmann-Landmann method. ${ }^{6}$ Major diastereomere 16: $R_{\mathrm{f}}=0.40 \quad(\mathrm{cHex} / \mathrm{TBME}$ 4:1). $[\alpha]_{\mathrm{D}}=-26.0\left(\mathrm{c}=0.97, \mathrm{CHCl}_{3}, \vartheta=24^{\circ} \mathrm{C}\right) .{ }^{1} \mathrm{H}-\mathrm{NMR}\left(300 \mathrm{MHz}, \mathrm{CDCl}_{3}\right): \delta=7.36-7.24(\mathrm{~m}, 10 \mathrm{H})$, 5.41-5.30 (m, 2H), 4.75 (d, $J=11.6 \mathrm{~Hz}, 1 \mathrm{H}), 4.57$ (d, $J=11.6 \mathrm{~Hz}, 1 \mathrm{H}), 4.50(\mathrm{~s}, 2 \mathrm{H}), 3.60-3.55$ (m, 1H), 3.54-3.50 (m, 1H), $3.46(\mathrm{t}, J=6.7 \mathrm{~Hz}, 2 \mathrm{H}), 3.44-3.41(\mathrm{~m}, 1 \mathrm{H}), 3.40-3.35(\mathrm{~m}, 1 \mathrm{H}), 3.30-$ $3.22(\mathrm{~m}, 1 \mathrm{H}), 3.10-3.03(\mathrm{~m}, 1 \mathrm{H}), 2.29-2.20(\mathrm{~m}, 1 \mathrm{H}), 2.17$ (d, J=4.0 Hz, 1H), 2.15-2.06 (m, 1H), 2.05-1.97 (m, 3H), 1.88-1.79 (m, 1H), 1.77-1.67 (m, 1H), 1.66-1.58 (m, 4H), 1.52-1.21 (m, 25H), $0.90(\mathrm{~s}, 9 \mathrm{H}), 0.88(\mathrm{~s}, 9 \mathrm{H}), 0.87(\mathrm{t}, J=6.9 \mathrm{~Hz}, 3 \mathrm{H}), 0.06(\mathrm{~s}, 3 \mathrm{H}), 0.05(\mathrm{~s}, 9 \mathrm{H}) .{ }^{13} \mathrm{C}-\mathrm{NMR}(75 \mathrm{MHz}$, $\left.\mathrm{CDCl}_{3}\right): \delta=139.0,138.8,130.2,129.6,128.3$ (2C), 128.2 (2C), 127.9 (2C), 127.6 (2C), 127.4 (2C), 82.1, 80.9, 79.5, 75.5, 74.4, 72.9, 71.3, 70.5, 33.5, 32.4, 31.8, 31.2, 29.84, 29.79 (2C), 29.6, 29.5, 29.0, 27.5, 27.2, 27.0, 26.6, 26.2, 25.9 (3C), 25.8 (3C), 25.7, 23.4, 22.6, 18.1, 18.0, 14.1, 4.0, -4.4 (2C), -4.7. IR (Film) 3471 (s br), 2928 (s), 2855 (s), 1462 (m), 1385 (w), 1245 (m), 1096 (s), $836(\mathrm{~m}), 775$ (m), $733(\mathrm{w}), 697$ (w). HRMS (ESI): m/z calcd. for $\mathrm{C}_{54} \mathrm{H}_{94} \mathrm{NaO}_{6} \mathrm{Si}_{2}\left(\mathrm{M}+\mathrm{Na}^{+}\right)$: 917.6481, found: 917.6468. Minor diastereomere 16a: $R_{\mathrm{f}}=0.45(c \mathrm{Hex} / \mathrm{TBME} 4: 1)$. $[\alpha]_{\mathrm{D}}=-25.6$ $\left(\mathrm{c}=1.00, \mathrm{CHCl}_{3}, \vartheta=24^{\circ} \mathrm{C}\right) .{ }^{1} \mathrm{H}-\mathrm{NMR}\left(300 \mathrm{MHz}, \mathrm{CDCl}_{3}\right): \delta 7.36-7.28(\mathrm{~m}, 10 \mathrm{H}), 5.41-5.31(\mathrm{~m}$, 2H), 4.77 (d, $J=11.5 \mathrm{~Hz}, 1 \mathrm{H}), 4.55$ (d, $J=11.5 \mathrm{~Hz}, 1 \mathrm{H}), 4.50$ (s, 2H), 3.49-3.44 (m, 1H), 3.46 (t, $J=6.7 \mathrm{~Hz}, 2 \mathrm{H}), 3.44-3.33(\mathrm{~m}, 3 \mathrm{H}), 3.30-3.22$ (m, 1H), 3.10-3.03 (m, 1H), 2.30-2.18 (m, 1H), $2.20(\mathrm{~d}, J=6.7 \mathrm{~Hz}, 1 \mathrm{H}), 2.16-2.06(\mathrm{~m}, 1 \mathrm{H}), 2.04-1.95(\mathrm{~m}, 3 \mathrm{H}), 1.89-1.76(\mathrm{~m}, 2 \mathrm{H}), 1.68-1.56(\mathrm{~m}$, 4H), 1.53-1.22 (m, 25H), $0.90(\mathrm{~s}, 9 \mathrm{H}), 0.88(\mathrm{~s}, 9 \mathrm{H}), 0.87(\mathrm{t}, J=7.0 \mathrm{~Hz}, 3 \mathrm{H}), 0.07(\mathrm{~s}, 3 \mathrm{H}), 0.06(\mathrm{~s}$, 3H), 0.05 (s, 6H). ${ }^{13} \mathrm{C}-\mathrm{NMR}:\left(75 \mathrm{MHz}, \mathrm{CDCl}_{3}\right): \delta=139.0,138.8,130.2,129.6,128.3$ (2C), 128.2 (2C), 127.9 (2C), 127.6 (2C), 127.4 (2C), 82.1, 81.7, 79.8, 75.6, 73.3, 72.9, 71.3, 70.5, 33.8, 33.5, $32.4,31.8,30.5,29.9,29.8$ (2C), 29.54, 29.45, 29.0, 27.5, 27.3, 27.0, 26.7, 26.2, 25.9 (3C), 25.8 (3C), 23.4, 22.6, 22.3, 18.1, 18.0, 14.1, -4.0, -4.1, -4.5, -4.7. IR (Film): 3461 (s br), 2928 (s),

${ }^{6}$ Landmann, R,; Hoffmann, R. W. Chem. Ber. 1987, 120, 331-333. 
2856 (s), 2063 (m), 1618 (w), 1455 (m), 1252 (m), 1094 (s), 836 (m), 775 (m), 733 (w), 697 (w). HRMS (ESI): $m / z$ calcd. for $\mathrm{C}_{54} \mathrm{H}_{94} \mathrm{NaO}_{6} \mathrm{Si}_{2}\left(\mathrm{M}+\mathrm{Na}^{+}\right)$: 917.6481, found: 917.6456.

\section{$(2 S, 3 R, 6 S)-3-t e r t-B u t y l-d i m e t h y l-s i l y l o x y-6-\{(2 ' S, 5 ' R)-5 ’-[(1 ' ’ S)-1$ '’-tert-butyl-dimethyl- silyloxy-9'’-hydroxy-nonyl]-tetrahydrofuran-2'-yl\}-2-decyl-tetrahydropyrane (17)}

A solution of the alcohol $(67 \mathrm{mg}, 75 \mu \mathrm{mol})$ in pyridine $(1 \mathrm{~mL})$ was cooled to $0^{\circ} \mathrm{C}$. Consecutively $\mathrm{TsCl}(57 \mathrm{mg}, 300 \mu \mathrm{mol})$ and DMAP $(0.9 \mathrm{mg}, 7.5 \mu \mathrm{mol})$ were added and the mixture was allowed to warm up to room temperature and stirred for $16 \mathrm{~h}$. After that it was treated with additional $\mathrm{TsCl}(57 \mathrm{mg}, 300 \mu \mathrm{mol})$ and DMAP $(0.9 \mathrm{mg}, 7.5 \mu \mathrm{mol})$. After $5 \mathrm{~h}$ stirring phosphate-buffer $(2 \mathrm{M}$, $\mathrm{pH} 7,2 \mathrm{~mL})$ and TBME $(5 \mathrm{~mL})$ were added. Aqueous workup using TBME $(3 \times 5 \mathrm{~mL})$ and sat. $\mathrm{NaCl}$-solution, drying with $\mathrm{Na}_{2} \mathrm{SO}_{4}$ followed by flash chromatography on silica (8 $\mathrm{g}$, pentane/TBME 15:1) afforded the tosylate $(67 \mathrm{mg}, 64 \mu \mathrm{mol}, 85 \%)$ as a colorless oil. $R_{\mathrm{f}}=0.19$ $(c \mathrm{Hex} / \mathrm{TBME} 15: 1), 0.43(c \mathrm{Hex} / \mathrm{TBME} 5: 1) .[\alpha]_{\mathrm{D}}=-31.5\left(\mathrm{c}=0.98, \mathrm{CHCl}_{3}, \vartheta=23^{\circ} \mathrm{C}\right) .{ }^{1} \mathrm{H}-\mathrm{NMR}$ $\left(300 \mathrm{MHz}, \mathrm{CDCl}_{3}\right) \delta=7.83-7.72(\mathrm{~m}, 2 \mathrm{H}), 7.37-7.20(\mathrm{~m}, 12 \mathrm{H}), 5.42-5.26(\mathrm{~m}, 2 \mathrm{H}), 4.69(\mathrm{~d}$, $J=11.5 \mathrm{~Hz}, 1 \mathrm{H}), 4.52-4.39(\mathrm{~m}, 1 \mathrm{H}), 4.44(\mathrm{~d}, J=11.5 \mathrm{~Hz}, 1 \mathrm{H}), 3.90-3.78(\mathrm{~m}, 1 \mathrm{H}), 3.46(\mathrm{t}$, $J=6.6 \mathrm{~Hz}, 2 \mathrm{H}), 3.35-3.16(\mathrm{~m}, 3 \mathrm{H}), 3.10-2.94(\mathrm{~m}, 1 \mathrm{H}), 2.41(\mathrm{~s}, 3 \mathrm{H}), 2.32-2.16(\mathrm{~m}, 1 \mathrm{H}), 2.15-2.03$ (m, 1H), 2.02-1.93 (m, 3H), 1.91-1.75 (m, 2H), 1.66-1.52 (m, 3H), 1.47-1.11 (m, 26H), 0.91-0.79 $(\mathrm{m}, 3 \mathrm{H}), 0.88(\mathrm{~s}, 9 \mathrm{H}), 0.84(\mathrm{~s}, 9 \mathrm{H}), 0.05(\mathrm{~s}, 6 \mathrm{H}), 0.01(\mathrm{~s}, 3 \mathrm{H}),-0.01(\mathrm{~s}, 3 \mathrm{H}) .{ }^{13} \mathrm{C}-\mathrm{NMR}(75 \mathrm{MHz}$, $\left.\mathrm{CDCl}_{3}\right) \delta=144.4,139.0,138.7,134.7,130.2,129,6$ (2C), 129.5, 128.3 (2C), 128.2 (2C), 127.8 (2C), 127.7 (2C), 127.6 (2C), 127.5, 127.4, 86.6, 82.1, 80.6, 79.8, 74.3, 72.93, 72.88, 71.3, 70.5, $34.5,33.5,32.4,31.8,29.8,29.53,29.49,29.43,29.0,27.3,26.7,26.4,26.2,25.9$ (3C), 25.8 (3C), 23.8, 23.5, 22.6, 21.6, 18.2, 18.0, 14.1, -4.0, -4.4, -4.7, -4.8. IR (Film) 2928 (s), 2855 (s), 1455 (m), 1362 (m), 1253 (m), 1177 (m), 1097 (s), 900 (w), 836 (m), 776 (m), 734 (w), 697 (w). HRMS (ESI): $m / z$ calcd. for $\mathrm{C}_{61} \mathrm{H}_{100} \mathrm{NaO}_{8} \mathrm{Si}_{2}\left(\mathrm{M}+\mathrm{Na}^{+}\right)$ber. 1071.6570 , found. 1071.6590 .

The tosylate $(67 \mathrm{mg}, 64 \mu \mathrm{mol})$ was dissolved in MeOH/EtOAc $(1: 1,2 \mathrm{~mL})$ and treated with $\mathrm{Pd} / \mathrm{C}$ (7 mg, $10 \mathrm{wt}-\%)$. After the black suspension was stirred for $5 \mathrm{~h}$ under a $\mathrm{H}_{2}$-atmosphere (atmospheric pressure) the catalyst was removed by filtration over a pad of celite ${ }^{\circledR}$. Removal of the solvents in vacuum followed by flash chromatography on silica (5 g, pentane/TBME $2: 1)$ furnished the diol $(45.4 \mathrm{mg}, 52.4 \mu \mathrm{mol}, 82 \%)$ as a colorless oil. $R_{\mathrm{f}}=0.39(\mathrm{cHex} / \mathrm{TBME} \mathrm{1:1)}$. 
$[\alpha]_{\mathrm{D}}=-33.5\left(\mathrm{c}=0.95, \mathrm{CHCl}_{3}, \vartheta=20^{\circ} \mathrm{C}\right) .{ }^{1} \mathrm{H}-\mathrm{NMR}\left(300 \mathrm{MHz}, \mathrm{CDCl}_{3}\right) \delta=7.78(\mathrm{pd}, \mathrm{J}=8.1 \mathrm{~Hz}$, 2H), $7.33(\mathrm{pd}, J=8.0 \mathrm{~Hz}, 2 \mathrm{H}), 4.56-4.45(\mathrm{~m}, 1 \mathrm{H}), 3.87-3.78(\mathrm{~m}, 1 \mathrm{H}), 3.64$ (t, $J=6.8 \mathrm{~Hz}, 2 \mathrm{H})$, 3.36-3.27 (m, 1H), 3.26-3.15 (m, 1H), 3.06-2.94 (m, 2H), $2.44(\mathrm{~s}, 3 \mathrm{H}), 2.01-1.93(\mathrm{~m}, 1 \mathrm{H}), 1.91-$ $1.19(\mathrm{~m}, 41 \mathrm{H}), 0.91-0.82(\mathrm{~m}, 3 \mathrm{H}), 0.88(\mathrm{~s}, 9 \mathrm{H}), 0.85(\mathrm{~s}, 9 \mathrm{H}), 0.05(\mathrm{~s}, 6 \mathrm{H}), 0.01(\mathrm{~s}, 3 \mathrm{H}),-0.01(\mathrm{~s}$, 3H). ${ }^{13} \mathrm{C}-\mathrm{NMR}\left(75 \mathrm{MHz}, \mathrm{CDCl}_{3}\right) \delta=144.4,134.7,129.6$ (2C), 127.8 (2C), 86.0, 82.2, 80.2, 74.2, 72.7, 71.3, 63.0, 34.3, 33.1, 32.8, 32.0, 31.9, 29.7, 29.6 (2C), 29.4, 29.35, 29.31, 29.26, 27.8, 26.8, 25.9 (3C), 25.8 (3C), 25.7, 25.5, 25.4, 23.3, 22.7, 21.6, 18.2, 18.0, 14.1, -4.0, -4.4, -4.73, 4.74. HRMS (ESI): $m / z$ calcd. for $\mathrm{C}_{47} \mathrm{H}_{90} \mathrm{NaO}_{8} \mathrm{Si}_{2}\left(\mathrm{M}+\mathrm{Na}^{+}\right)$893.5787, found 893.5821.

The diol $(26 \mathrm{mg}, 30 \mu \mathrm{mol})$ was dissolved in pyridine $(1 \mathrm{~mL})$ and heated to $115^{\circ} \mathrm{C}$ for $1 \mathrm{~h}$. The pyridine was evaporated in vacuum and the residue was purified by flash chromatography on silica (2 g, pentane/TBME 10:1) to afford alcohol 17 (20.8 mg, $30 \mu \mathrm{mol}, 99 \%)$ as a colorless oil. $R_{\mathrm{f}}=0.30(\mathrm{cHex} / \mathrm{TBME} 2: 1) .[\alpha]_{\mathrm{D}}=-20.8\left(\mathrm{c}=0.86, \mathrm{CHCl}_{3}, \vartheta=21{ }^{\circ} \mathrm{C}\right) .{ }^{1} \mathrm{H}-\mathrm{NMR}(300 \mathrm{MHz}$, $\left.\mathrm{CDCl}_{3}\right): \delta=3.87-3.75(\mathrm{~m}, 2 \mathrm{H}), 3.67-3.60(\mathrm{~m}, 1 \mathrm{H}), 3.64(\mathrm{t}, J=6.6 \mathrm{~Hz}, 2 \mathrm{H}), 3.30-3.16(\mathrm{~m}, 2 \mathrm{H})$, 3.06-2.95 (m, 1H), 2.01-1.92 (m, 1H), 1.86-1.62 (m, 5H), 1.60-1.43 (m, 8H), 1.37-1.21 (m, 27H), 0.92-0.83 (m, 3H), $0.88(\mathrm{~s}, 18 \mathrm{H}), 0.07(\mathrm{~s}, 3 \mathrm{H}), 0.055(\mathrm{~s}, 3 \mathrm{H}), 0.047(\mathrm{~s}, 6 \mathrm{H}) .{ }^{13} \mathrm{C}-\mathrm{NMR}(75 \mathrm{MHz}$, $\left.\mathrm{CDCl}_{3}\right): \delta=82.6,82.2,81.1,79.4,74.2,71.3,63.1,33.5,32.8,32.7,32.2,31.9,29.9,29.8,29.71$, 29.67 (2C), 29.6, 29.40, 29.36, 27.9, 27.0, 26.8, 26.0 (3C), 25.8 (3C), 25.7, 25.6, 25.4, 22.7, 18.3, 18.0, 14.1, -4.0, -4.1, -4.68, -4.71. IR (Film): 3441 (b m), 2927 (s), 2855 (s), 1463 (m), 1360 (w), 1251 (m), 1094 (s), 889 (w), 836 (m), 775 (m), 734 (w). HRMS (ESI): m/z calcd. for $\mathrm{C}_{40} \mathrm{H}_{82} \mathrm{NaO}_{5} \mathrm{Si}_{2}\left(\mathrm{M}+\mathrm{Na}^{+}\right):$721.5593, found: 721.5589 .

\section{$(2 S, 3 R, 6 S)-3-t e r t-B u t y l-d i m e t h y l s i l y l o x y-6-\{(2 ' S, 5 ' R)-5$ '-[(1'’S)-1'’-tert-butyldimethylsilyl- oxy-9',-(1','phenyl-1H-tetrazolylsulfonyl)-nonyl]-tetrahydrofuran-2'-yl\}-2-decyl-tetra- hydropyrane (18)}

A solution of alcohol $17(29 \mathrm{mg}, 41 \mu \mathrm{mol}), \mathrm{PPh}_{3}(16 \mathrm{mg}, 62 \mu \mathrm{mol})$ and 1-phenyl-1H-tetrazol-5thiol $(15 \mathrm{mg}, 82 \mu \mathrm{mol})$ in THF $(0.5 \mathrm{~mL})$ was treated with DIAD $(15.6 \mu \mathrm{L}, 74 \mu \mathrm{mol})$ at $0{ }^{\circ} \mathrm{C}$ and stirred for $3 \mathrm{~h}$ at $\mathrm{rt}$. The solvent was evaporated in vacuum and the residue was purified by flash chromatography on silica ( $3 \mathrm{~g}$, pentane/TBME 15:1) to give the thioether $(33.5 \mathrm{mg}, 39 \mu \mathrm{mol}$, $95 \%)$ as a colorless oil. $R_{\mathrm{f}}=0.39(\mathrm{cHex} / \mathrm{TBME} 7: 1) .[\alpha]_{\mathrm{D}}=-15.7\left(\mathrm{c}=0.84, \mathrm{CHCl}_{3}, \vartheta=21{ }^{\circ} \mathrm{C}\right)$. 
${ }^{1} \mathrm{H}-\mathrm{NMR}\left(300 \mathrm{MHz}, \mathrm{CDCl}_{3}\right): \delta=7.63-7.48(\mathrm{~m}, 5 \mathrm{H}), 3.87-3.73(\mathrm{~m}, 2 \mathrm{H}), 3.68-3.58(\mathrm{~m}, 1 \mathrm{H}), 3.39$ (t, $J=7.3 \mathrm{~Hz}, 2 \mathrm{H}), 3.29-3.17(\mathrm{~m}, 2 \mathrm{H}), 3.07-2.94(\mathrm{~m}, 1 \mathrm{H}), 2.03-1.92(\mathrm{~m}, 1 \mathrm{H}), 1.87-1.37(\mathrm{~m}, 15 \mathrm{H})$, 1.36-1.20 (m, 24H), 0.92-0.83 (m, 3H), 0.87 (s, 18H), 0.07 (s, 3H), $0.05(\mathrm{~s}, 3 \mathrm{H}), 0.04(\mathrm{~s}, 6 \mathrm{H})$.

${ }^{13} \mathrm{C}-\mathrm{NMR}\left(75 \mathrm{MHz}, \mathrm{CDCl}_{3}\right): \delta=154.5,133.8,130.0,129.7,123.8(2 \mathrm{C}), 82.6,82.2,81.1,79.3$, 74.7, 71.3, 33.5, 33.4, 32.7, 32.2, 31.9, 29.8, 29.74, 29.69, 29.65 (2C), 29.5, 29.3, 29.1, 29.0, 28.7, 27.9, 27.0, 26.8, 26.0 (3C), 25.8 (3C), 25.6, 25.4, 22.7, 18.3, 18.0, 14.1, -4.0, -4.1, -4.69, 4.72. HRMS (ESI): $m / z$ calcd. for $\mathrm{C}_{47} \mathrm{H}_{8} \mathrm{NaO}_{5} \mathrm{Si}_{2}\left(\mathrm{M}+\mathrm{Na}^{+}\right): 721.5593$, found 721.5589 .

To a solution of the thioether $(29.8 \mathrm{mg}, 34.7 \mu \mathrm{mol})$ in $\mathrm{CH}_{2} \mathrm{Cl}_{2}(1 \mathrm{~mL})$ was added $m$ CPBA ( $30 \mathrm{mg}$, $121 \mu \mathrm{mol})$ at $0{ }^{\circ} \mathrm{C}$. The mixture was stirred at $\mathrm{rt}$ for $18 \mathrm{~h}$. Subsequently $\mathrm{Na}_{2} \mathrm{~S}_{2} \mathrm{O}_{3}$-solution $(20 \%$ in $\mathrm{H}_{2} \mathrm{O}, 2 \mathrm{~mL}$ ) and sat. $\mathrm{NaHCO}_{3}$-solution $(2 \mathrm{~mL})$ were added. Aqueous workup with $\mathrm{CH}_{2} \mathrm{Cl}_{2}$ $(4 \times 6 \mathrm{~mL})$ and sat. $\mathrm{NaCl}$-solution, drying with $\mathrm{Na}_{2} \mathrm{SO}_{4}$ followed by flash chromatography on silica (3 g, pentane/TBME 15:1) afforded sulfone $18(24.1 \mathrm{mg}, 27.1 \mu \mathrm{mol}, 78 \%)$ as a colorless oil. $R_{\mathrm{f}}=0.22 \quad(\mathrm{cHex} / \mathrm{TBME} \quad 10: 1) . \quad[\alpha]_{\mathrm{D}}=-15.7 \quad\left(\mathrm{c}=0.91, \quad \mathrm{CHCl}_{3}, \quad \vartheta=24^{\circ} \mathrm{C}\right) . \quad{ }^{1} \mathrm{H}-\mathrm{NMR}$ $\left(300 \mathrm{MHz}, \mathrm{CDCl}_{3}\right): \delta=7.72-7.67(\mathrm{~m}, 2 \mathrm{H}), 7.65-7.67(\mathrm{~m}, 3 \mathrm{H}), 3.86-3.76(\mathrm{~m}, 2 \mathrm{H}), 3.75-3.69(\mathrm{~m}$, 2H), 3.66-3.57 (m, 1H), 3.29-3.17 (m, 2H), 3.05-2.95 (m, 1H), 2.02-1.89 (m, 3H), 1.87-1.61 (m, $5 \mathrm{H}), 1.57-1.21(\mathrm{~m}, 32 \mathrm{H}), 0.90-0.83(\mathrm{~m}, 3 \mathrm{H}), 0.87(\mathrm{~s}, 18 \mathrm{H}), 0.07(\mathrm{~s}, 3 \mathrm{H}), 0.052(\mathrm{~s}, 3 \mathrm{H}), 0.047(\mathrm{~s}$, 6H). ${ }^{13} \mathrm{C}-\mathrm{NMR}\left(75 \mathrm{MHz}, \mathrm{CDCl}_{3}\right): \delta=153.5,133.1,131.4,129.7$ (2C), 125.1 (2C), 82.6, 82.2, 81.1, 79.3, 74.7, 71.3, 56.1, 33.5, 32.7, 32.2, 31.9, 29.78, 29.75, 29.71, 29.67 (2C), 29.35, 29.26, $28.9,28.2,27.9,27.0,26.8,26.0$ (3C), 25.8 (3C), 25.5, 25.4, 22.7, 22.0, 18.3, 18.0, 14.1, -4.0, 4.1, -4.67, -4.70. IR (Film): 2927 (s), 2855 (m), 1597 (w), 1498 (w), 1427 (m), 1344 (m), 1251 (m), 1153 (m), 1095 (s), 836 (s), 775 (m). HRMS (ESI): m/z calcd. for $\mathrm{C}_{47} \mathrm{H}_{86} \mathrm{~N}_{4} \mathrm{NaO}_{6} \mathrm{SSi}_{2}$ $\left(\mathrm{M}+\mathrm{Na}^{+}\right)$: 913.5709 , found: 913.5699 .

\section{4-O,15-O,23-O-Tris(tert-butyldimethylsilyloxy)-6,7-dehydro-jimenezin (20)}

A solution of sulfone $18(23.0 \mathrm{mg}, 25.8 \mu \mathrm{mol})$ in THF $(1 \mathrm{~mL})$ was cooled to $-78^{\circ} \mathrm{C}$ and treated with LiHMDS ( $1 \mathrm{M}$ in THF, $39 \mu \mathrm{L}, 38.7 \mu \mathrm{mol}$ ), whereupon the solution turned yellow. After $40 \mathrm{~min}$ at $-78^{\circ} \mathrm{C}$ aldehyde $19(13.9 \mathrm{mg}, 46.9 \mu \mathrm{mol})$ dissolved in THF $(0.5 \mathrm{~mL})$ was added slowly. The mixture was allowed to warm up to $-10{ }^{\circ} \mathrm{C}$ within $2-3 \mathrm{~h}$ and the reaction was quenched by addition of phosphate-buffer $(2 \mathrm{M}, \mathrm{pH}, 1 \mathrm{~mL})$ and $\mathrm{H}_{2} \mathrm{O}(1 \mathrm{~mL})$ followed by 
aqueous workup with TBME $(3 \times 5 \mathrm{~mL})$ and sat. NaCl-solution. After evaporation of the solvent in vacuum the crude mixture was purified by flash chromatography on silica ( $4 \mathrm{~g}$, pentane/TBME 10:1). This first chromatography enabled the removal of the excess of aldehyde 19. The separation of traces not reacted sulfone 18 and product 20 was achieved by a second chromatography on silica (4 g, cyclohexane/acetone 15:1) affording the desired olefin 20 as an E/Z-mixture (23.1 mg, $23.1 \mu \mathrm{mol}, 93 \%) . R_{\mathrm{f}}=0.17$ (cHex/TBME 10:1), 0.44 (cHex/acetone 7:1).

${ }^{1} \mathrm{H}-\mathrm{NMR}$ (300 MHz, $\mathrm{CDCl}_{3}$, E/Z-mixture): $\delta=7.13-7.09$ (m, 1H), 5.52-5.32 (m, 2H), 5.05-4.95 (m, 1H), 4.07-3.93 (m, 1H), 3.88-3.74 (m, 2H), 3.67-3.55 (m, 1H), 3.29-3.17 (m, 2H), 3.06-2.94 (m, 1H), 2.49-2.33 (m, 2H), 2.29-2.13 (m, 2H), 2.03-1.92 (m, 3H), 1.86-1.62 (m, 5H), 1.56-1.40 $(\mathrm{m}, 6 \mathrm{H}), 1.41(\mathrm{~d}, J=6.8 \mathrm{~Hz}, 3 \mathrm{H}), 1.38-1.19(\mathrm{~m}, 29 \mathrm{H}), 0.879(\mathrm{~s}, 9 \mathrm{H}), 0.876(\mathrm{~m}, 9 \mathrm{H}), 0.867(\mathrm{~m}$, 9H), 0.07 (s, 3H), 0.06 (s, 3H), 0.05 (s, 9H), 0.01 (s, 3H). ${ }^{13} \mathrm{C}-\mathrm{NMR}\left(75 \mathrm{MHz}, \mathrm{CDCl}_{3}\right.$, E/Zmixture): $\delta=173.9,151.4,133.8,132.4,131.0,125.4,124.7,82.6,82.2,81.1,79.3,74.8,71.3$, 70.14, 70.11, 40.6, 35.1, 33.5, 32.7, 32.6, 32.2, 31.9, 29.9, 29.8, 29.71, 29.67 (2C), 29.61, 29.55, 29.50, 29.39, 29.35, 29.28, 27.9, 27.6, 27.0, 26.9, 26.0 (3C), 25.9 (3C), 25.8 (3C), 25.6, 25.4, $22.7,19.0,18.3,18.1,18.0,14.1,-4.0$ (2C), -4.1 (2C), -4.37, -4.38, -4.5, -4.6, -4.67 (2C), -4.71 (2C). HRMS (ESI): $\mathrm{m} / z$ calcd. for $\mathrm{C}_{55} \mathrm{H}_{106} \mathrm{NaO}_{7} \mathrm{Si}_{3}\left(\mathrm{M}+\mathrm{Na}^{+}\right)$: 985.7139 , found: 985.7142 .

\section{Jimenezin}

The olefin $20(11.0 \mathrm{mg}, 11.4 \mu \mathrm{mol})$ and [( $\left.\left.\mathrm{PPh}_{3}\right)_{3} \mathrm{RhCl}\right]$ (Wilkinson's-catalyst, $10.5 \mathrm{mg}$, $11.4 \mu \mathrm{mol}$ ) were dissolved in benzene (HPLC-grade, $1 \mathrm{~mL}$ ) and degassed at $-20^{\circ} \mathrm{C}$. Afterwards the mixture was stirred for $16 \mathrm{~h}$ under a $\mathrm{H}_{2}$-atmosphere (atmospheric pressure). The solvent was evaporated in vacuum and the crude mixture was purified by flash chromatography on silica ( $1 \mathrm{~g}$, cyclohexane/MTBE 10:1) affording tri-TBS-jimenezin (10.9 mg, $11.3 \mu \mathrm{mmol}, 99 \%)$ as a colorless oil.

A solution of tris-TBS-jimenezin $(12.0 \mathrm{mg}, 12.4 \mu \mathrm{mmol})$ in $\mathrm{CH}_{2} \mathrm{Cl}_{2}(0.5 \mathrm{~mL})$ was cooled to $0{ }^{\circ} \mathrm{C}$ and treated dropwise with a HF-solution $(5 \%$ in $\mathrm{MeCN}, 200 \mu \mathrm{L})$. After the mixture was stirred at rt for $2 \mathrm{~h}$ phosphate-buffer $(2 \mathrm{M}, \mathrm{pH}, 1 \mathrm{~mL})$ and $\mathrm{H}_{2} \mathrm{O}(1 \mathrm{~mL})$ were added, the layers were separated and the aqueous layer was extracted with $\mathrm{CHCl}_{3} / \mathrm{PrOH}(5: 1,3 \times 5 \mathrm{~mL})$. The solvent was evaporated in vacuum and the residue was purified by flash chromatography on silica $(1 \mathrm{~g}$, 
$\left.\mathrm{CHCl}_{3} / \mathrm{MeOH} 19: 1\right)$ to afford (-)-jimenezin $(7.7 \mathrm{mg}, 12.4 \mu \mathrm{mol}, 100 \%)$ as a colorless oily to waxen substance. $R_{\mathrm{f}}=0.20\left(\mathrm{CHCl}_{3} / \mathrm{MeOH} 19: 1\right) .[\alpha]_{\mathrm{D}}=-10.4\left(\mathrm{c}=0.75, \mathrm{MeOH}, \vartheta=21{ }^{\circ} \mathrm{C}\right) .{ }^{1} \mathrm{H}$ (600 MHz, $\left.\mathrm{CDCl}_{3}\right): \delta=7.18\left(\mathrm{~m}_{\mathrm{c}}, 35-\mathrm{H}\right), 5.05$ (dddq, $\left.J=6.8,1.3,1.3,1.3 \mathrm{~Hz}, 36-\mathrm{H}\right), 3.96-3.92$ (m, 1H, 19-H), 3.91-3.88 (m, 1H, 16-H), 3.88-3.80 (m, 1H, 4-H), 3.39-3.32 (m, 1H, 15-H), 3.27 (ddd, $J=10.4,9.4,4.4 \mathrm{~Hz}, 1 \mathrm{H}, 23-\mathrm{H}$ ), 3.23 (ddd, $J=11.4,2.3,2.3 \mathrm{~Hz}, 1 \mathrm{H}, 20-\mathrm{H}$ ), 3.08 (bd, $J=4.2 \mathrm{~Hz}, 1 \mathrm{H}, \mathrm{OH}$ ), 3.04 (ddd, $J=9.2,9.0,2.1 \mathrm{~Hz}, 1 \mathrm{H}, 24-\mathrm{H}$ ), 2.53 (dddd, $J=15.2,3.2,1.6$, $1.6 \mathrm{~Hz}, 1 \mathrm{H}, 3-\mathrm{H}^{\mathrm{a}}$ ), 2.40 (dddd, $\left.J=15.2,8.2,1.5,1.5 \mathrm{~Hz}, 1 \mathrm{H}, 3-\mathrm{H}^{\mathrm{b}}\right), 2.35-2.19(\mathrm{~m}, 1 \mathrm{H}, \mathrm{OH}), 2.12$ (dddd, $\left.J=12.0,4.0,3.9,3.6 \mathrm{~Hz}, 1 \mathrm{H}, 22-\mathrm{H}^{\mathrm{a}}\right), 2.04-1.97\left(\mathrm{~m}, 1 \mathrm{H}, 18-\mathrm{H}^{\mathrm{a}}\right), 1.96-1.21(\mathrm{~m}, 45 \mathrm{H}, 5-$ 14,17,21,25-33- $\left.\mathrm{H}_{2}, 18,22-\mathrm{H}^{\mathrm{b}}, \mathrm{OH}\right), 1.43\left(\mathrm{~d}, J=6.6 \mathrm{~Hz}, 3 \mathrm{H}, 37-\mathrm{H}_{3}\right), 0.88$ (t, $J=6.9 \mathrm{~Hz}, 3 \mathrm{H}, 34-$ $\left.\mathrm{H}_{3}\right) .{ }^{13} \mathrm{C}-\mathrm{NMR}\left(125 \mathrm{MHz}, \mathrm{CDCl}_{3}\right): \delta=174.6(\mathrm{C}-1), 151.7$ (C-35), $131.2(\mathrm{C}-2), 82.40(\mathrm{C}-16)$, 82.36 (C-24), 80.9 (C-19), 79.0 (C-20), 78.0 (C-36), 73.9 (C-15), 70.6 (C-23), 70.0 (C-4), 37.4 (C-5), 34.9 (C-14), 33.4 (C-3), 32.9 (C-22), 32.0, 31.9 (C-32), 29.73, 29.70, 29.6, 29.5, 29.4, 28.3 (C-18), 28.1 (C-17), 28.0 (C-21), 25.9, 25.6, 25.5 (C-25), 22.7 (C-33), 19.1 (C-37), 14.1 (C-34). HRMS (ESI): $\mathrm{m} / z$ calcd. for $\mathrm{C}_{23} \mathrm{H}_{40} \mathrm{NaO}_{3} \mathrm{Si}\left(\mathrm{M}+\mathrm{Na}^{+}\right): 645.4701$, found: 645.4694 . 


\section{Comparison of ${ }^{13} \mathrm{C}$-NMR-shifts of natural and synthetic Jimenezin}

$\left(125 \mathrm{MHz}, \mathrm{CDCl}_{3}\right)$

\begin{tabular}{|c|c|c|c|c|}
\hline Pos. & $\begin{array}{l}\text { Mata et al. } \\
\text { (isolation 1998) }\end{array}$ & $\begin{array}{l}\text { Takahashi et al. }^{\mathbf{8}} \\
\text { (total synthesis 1999) }\end{array}$ & $\begin{array}{c}\text { Lee et al. } \\
\text { (total synthesis 2005) }\end{array}$ & $\begin{array}{c}\text { Koert et al. } \\
\text { (total synthesis 2005) }\end{array}$ \\
\hline 1 & 174.6 & 174.6 & 174.6 & 174.6 \\
\hline 35 & 151.7 & 151.8 & 151.9 & 151.7 \\
\hline 2 & 131.2 & 131.2 & 131.2 & 131.2 \\
\hline 16 & 82.4 & 82.4 & 82.4 & 82.40 \\
\hline 24 & 82.3 & 82.3 & 82.3 & 82.36 \\
\hline 19 & 80.9 & 80.9 & 80.9 & 80.9 \\
\hline 20 & 79.0 & 79.0 & 79.0 & 79.0 \\
\hline 36 & 78.0 & 78.0 & 78.0 & 78.0 \\
\hline 15 & 73.9 & 73.9 & 73.9 & 73.9 \\
\hline 23 & 70.6 & 70.5 & 70.6 & 70.6 \\
\hline 4 & 70.0 & 70.0 & 70.0 & 70.0 \\
\hline 5 & 37.4 & 37.4 & 37.4 & 37.4 \\
\hline 14 & 34.9 & 34.9 & 34.9 & 34.9 \\
\hline 3 & 33.3 & 33.5 & 33.4 & 33.4 \\
\hline$*$ & & 33.3 & & \\
\hline 22 & 32.9 & 32.9 & 32.9 & 32.9 \\
\hline$*$ & $25-33$ & 32.0 & 32.0 & 32.0 \\
\hline 32 & 31.9 & 31.9 & 31.9 & 31.9 \\
\hline$*$ & $25-33$ & & & 29.73 \\
\hline$*$ & $25-33$ & 29.7 & 29.7 & 29.70 \\
\hline$*$ & $25-33$ & 29.6 & 29.6 & 29.6 \\
\hline$*$ & $25-33$ & 29.5 & 29.5 & 29.5 \\
\hline$*$ & $25-33$ & 29.4 & 29.3 & 29.4 \\
\hline 18 & 28.3 & 28.3 & & 28.3 \\
\hline 17 & 28.0 & 28.1 & 28.1 & 28.1 \\
\hline 21 & 27.9 & 27.9 & 27.9 & 28.0 \\
\hline$*$ & $25-33$ & 25.9 & 25.9 & 25.9 \\
\hline$*$ & $25-33$ & 25.6 & 25.6 & 25.6 \\
\hline 25 & 25.5 & 25.5 & 25.5 & 25.5 \\
\hline 33 & 22.7 & 22.7 & 22.7 & 22.7 \\
\hline 37 & 19.1 & 19.1 & 19.1 & 19.1 \\
\hline 34 & 14.1 & 14.1 & 14.1 & 14.1 \\
\hline
\end{tabular}

* not assigned.

${ }^{7}$ Chávez, D., Acevedo, L. A.; Mata, R. J. Nat. Prod. 1998, 61, 419.

${ }^{8}$ Takahashi, S.; Maeda, K.; Hirota, S.; Nakata, T. Org. Lett. 1999, 1, 2025.

${ }^{9}$ Hwang, C. H.; Keum, G., Sohn, K. I.; Lee, D. H.; Lee, E. Tetrahedron Lett. 2005, 46, 6621. 


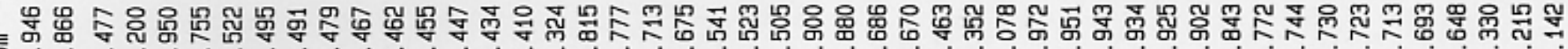

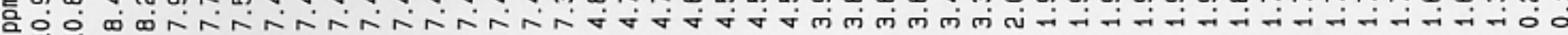
ij

$\left({ }^{1} \mathrm{H}-\mathrm{NMR}, \mathrm{CDCl}_{3}, 300 \mathrm{MHz}\right)$
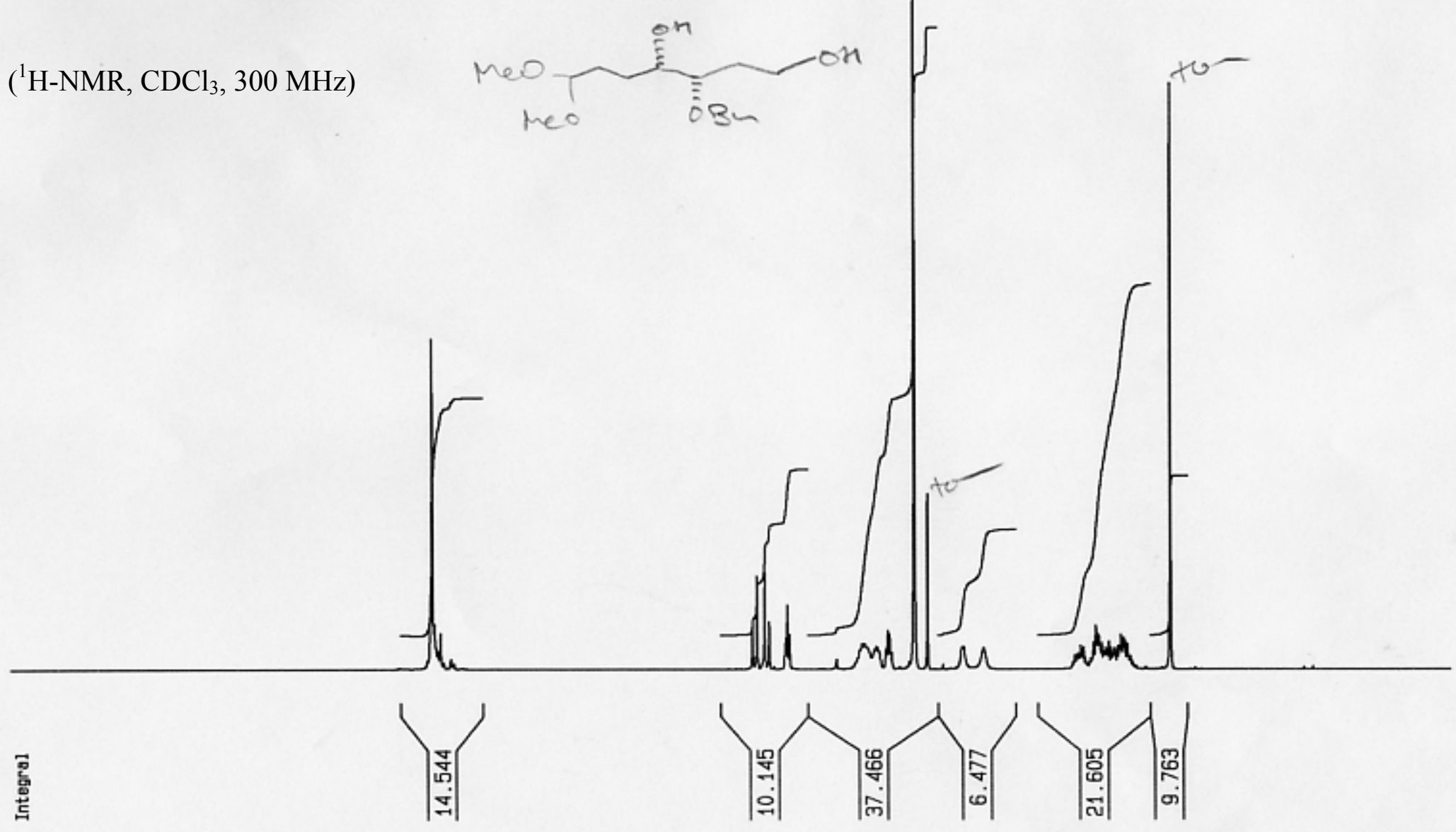

ppm

6

4

2 
( $\left.{ }^{1} \mathrm{H}-\mathrm{NMR}, \mathrm{CDCl}_{3}, 300 \mathrm{MHz}\right)$<smiles>COC(CC[C@@H](O)[C@@H](CC[OH2+])Cc1ccccc1)OC</smiles>

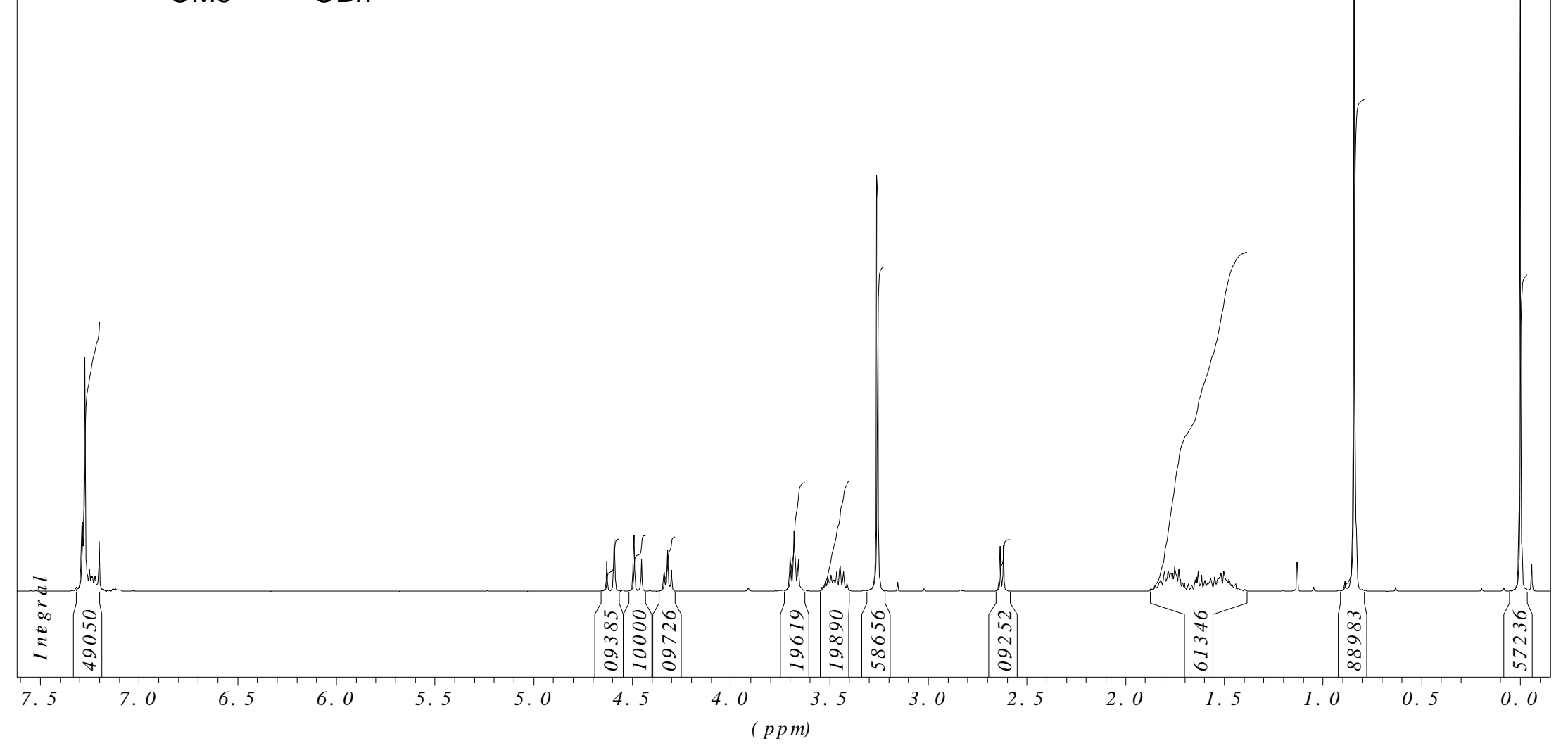




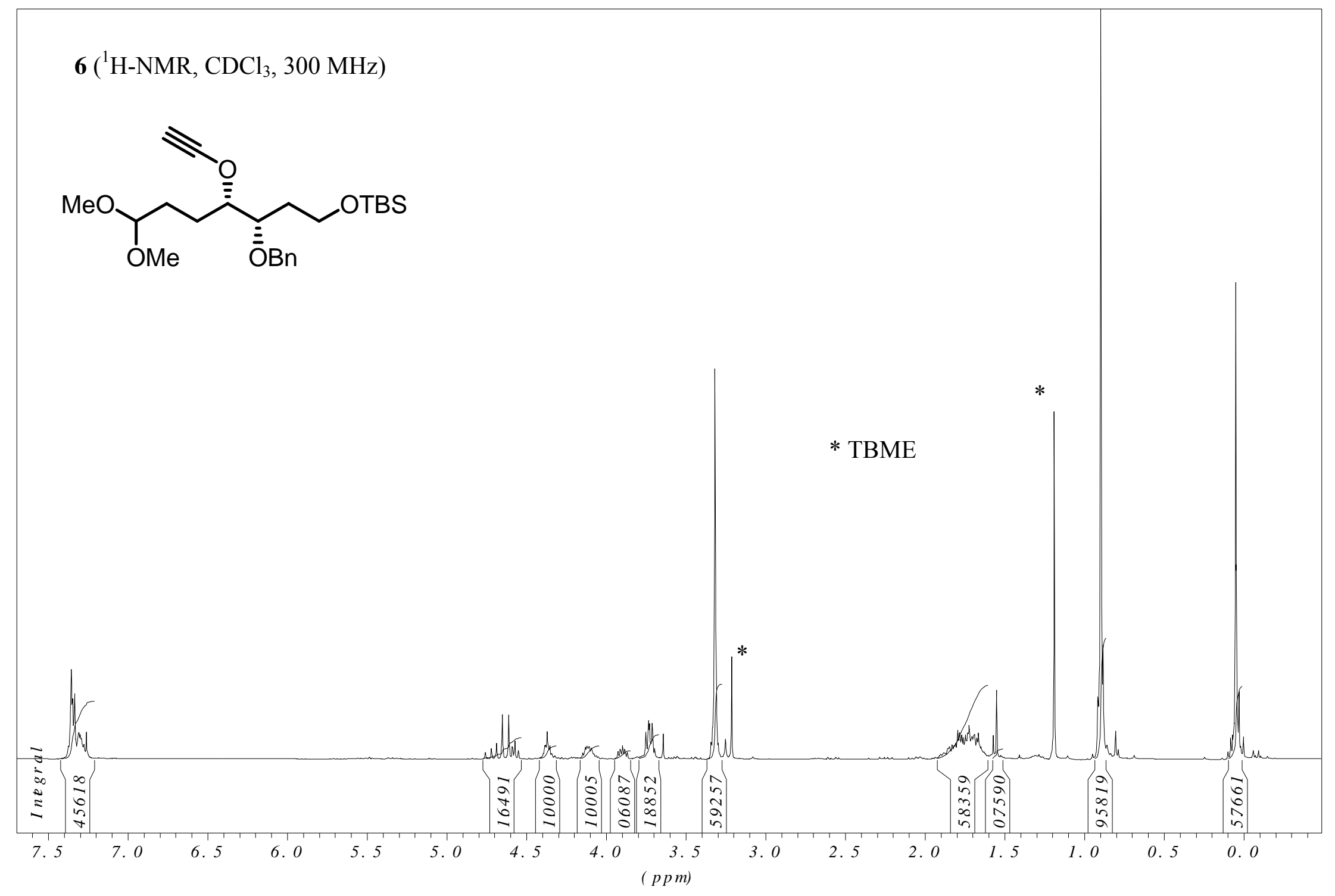




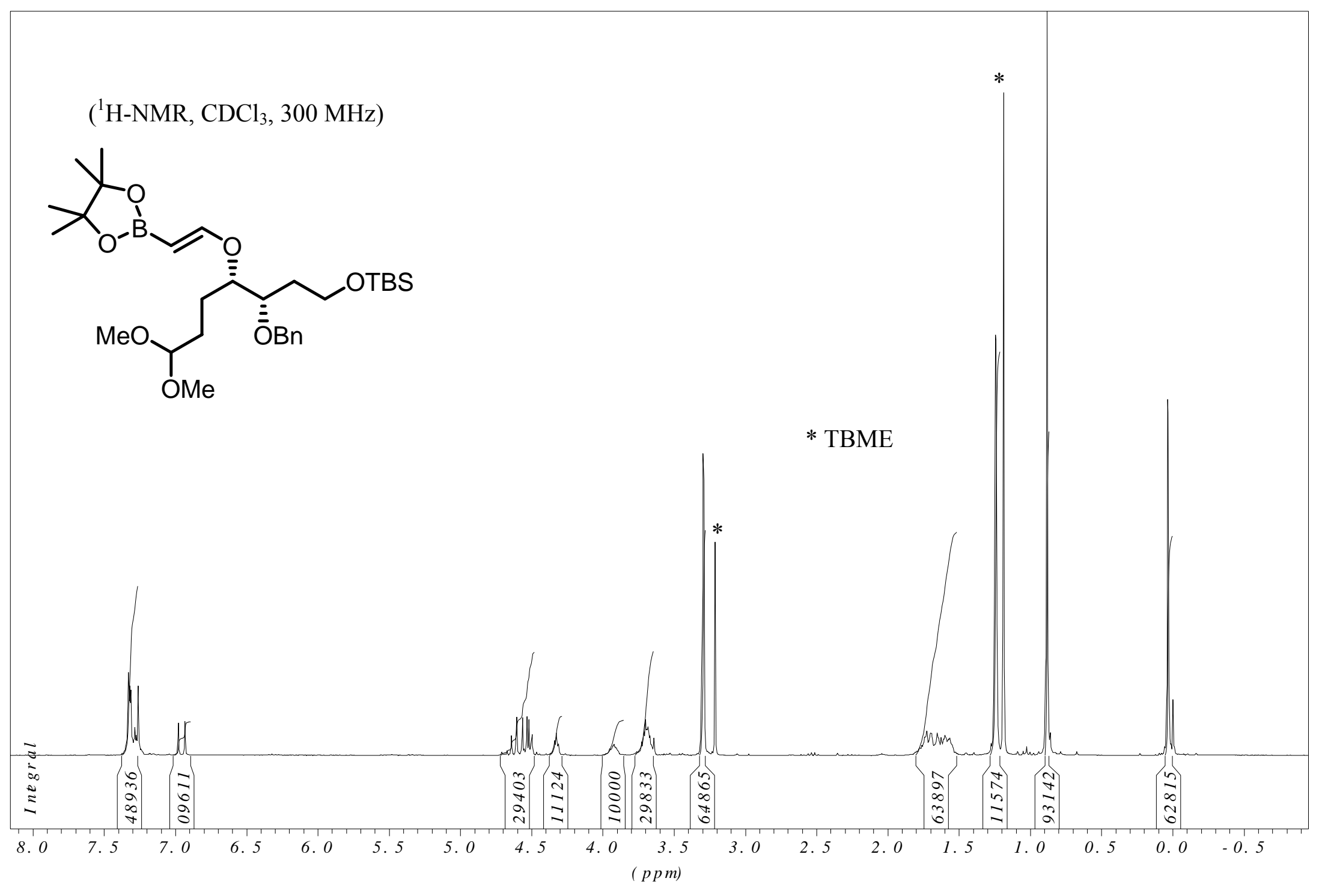


$7\left({ }^{1} \mathrm{H}-\mathrm{NMR}, \mathrm{CDCl}_{3}, 300 \mathrm{MHz}\right)$

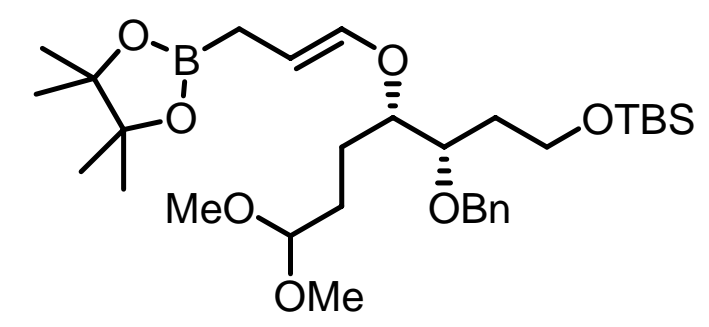

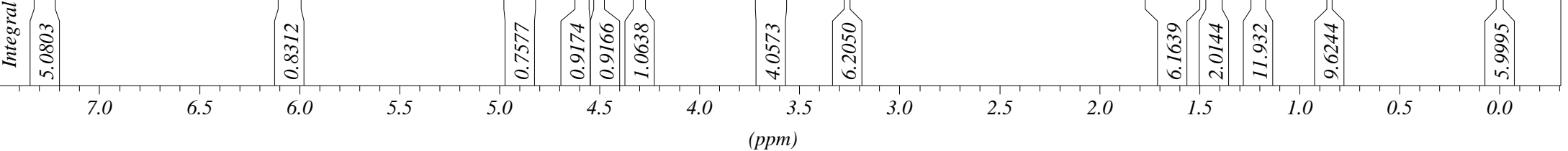




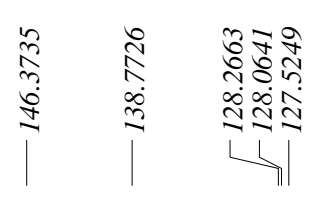

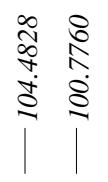

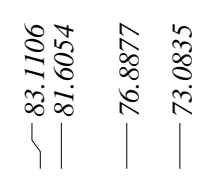

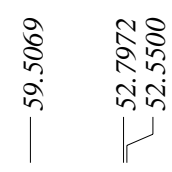

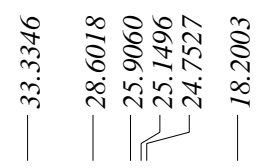

$7\left({ }^{13} \mathrm{C}-\mathrm{NMR}, \mathrm{CDCl}_{3}, 75 \mathrm{MHz}\right)$

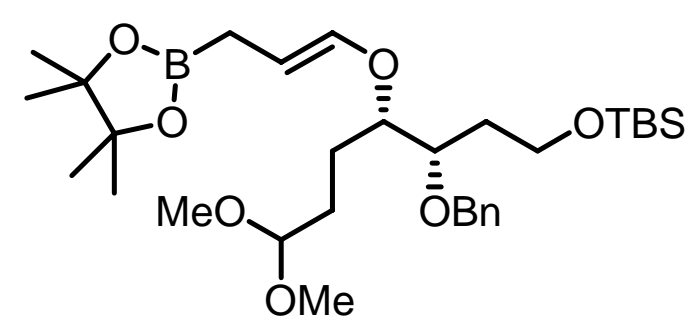

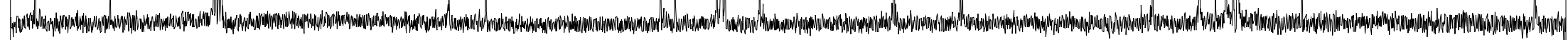




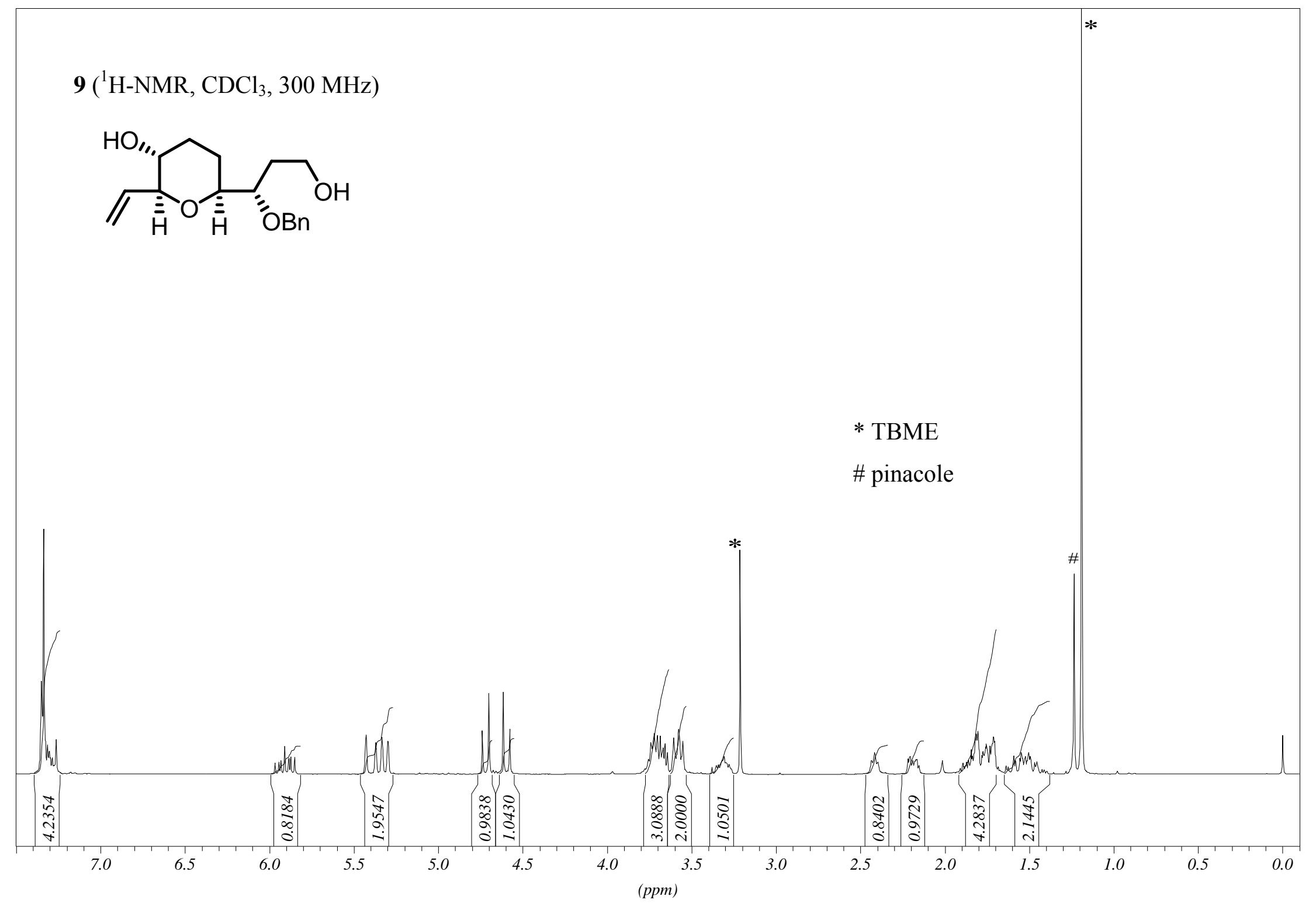




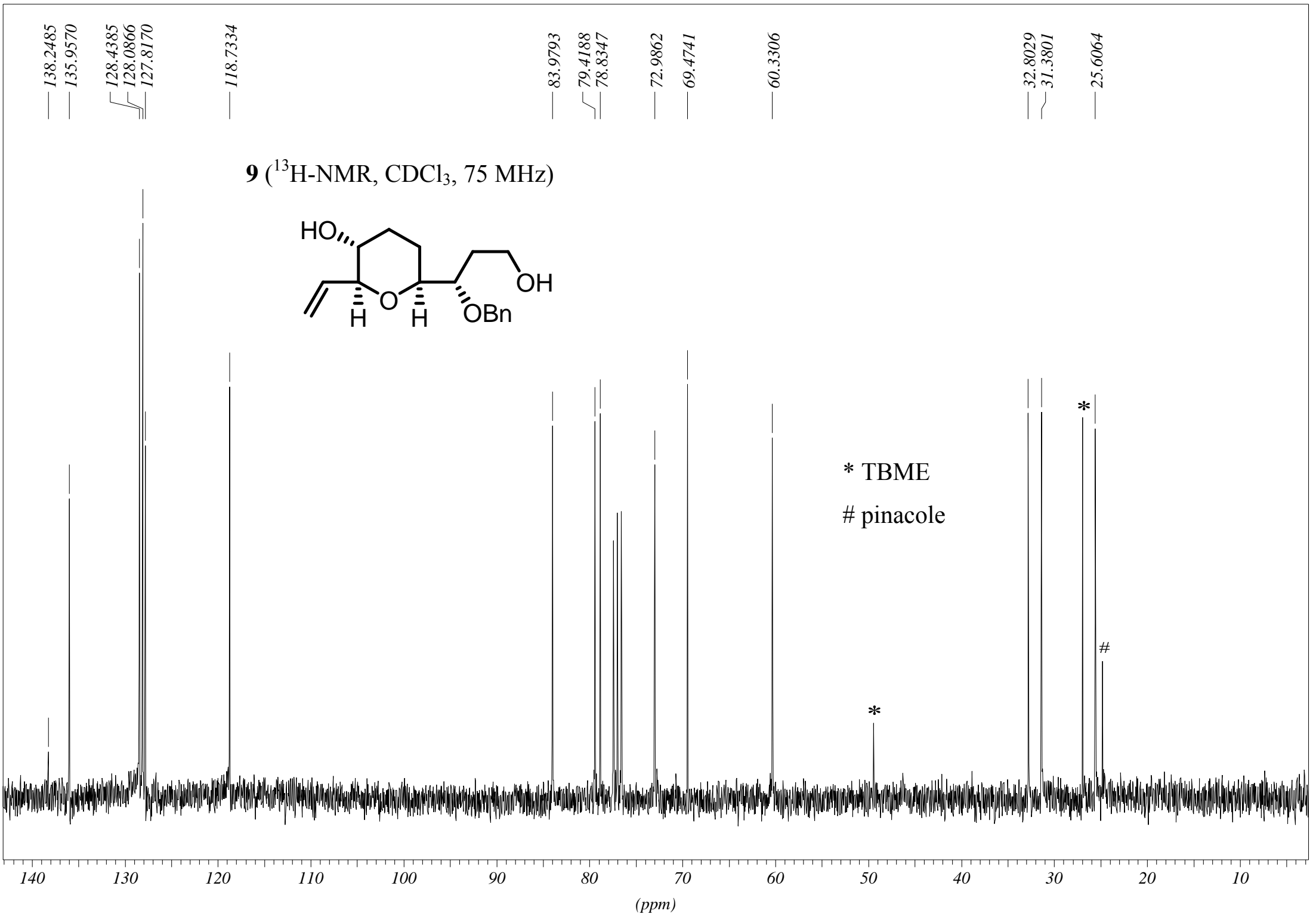




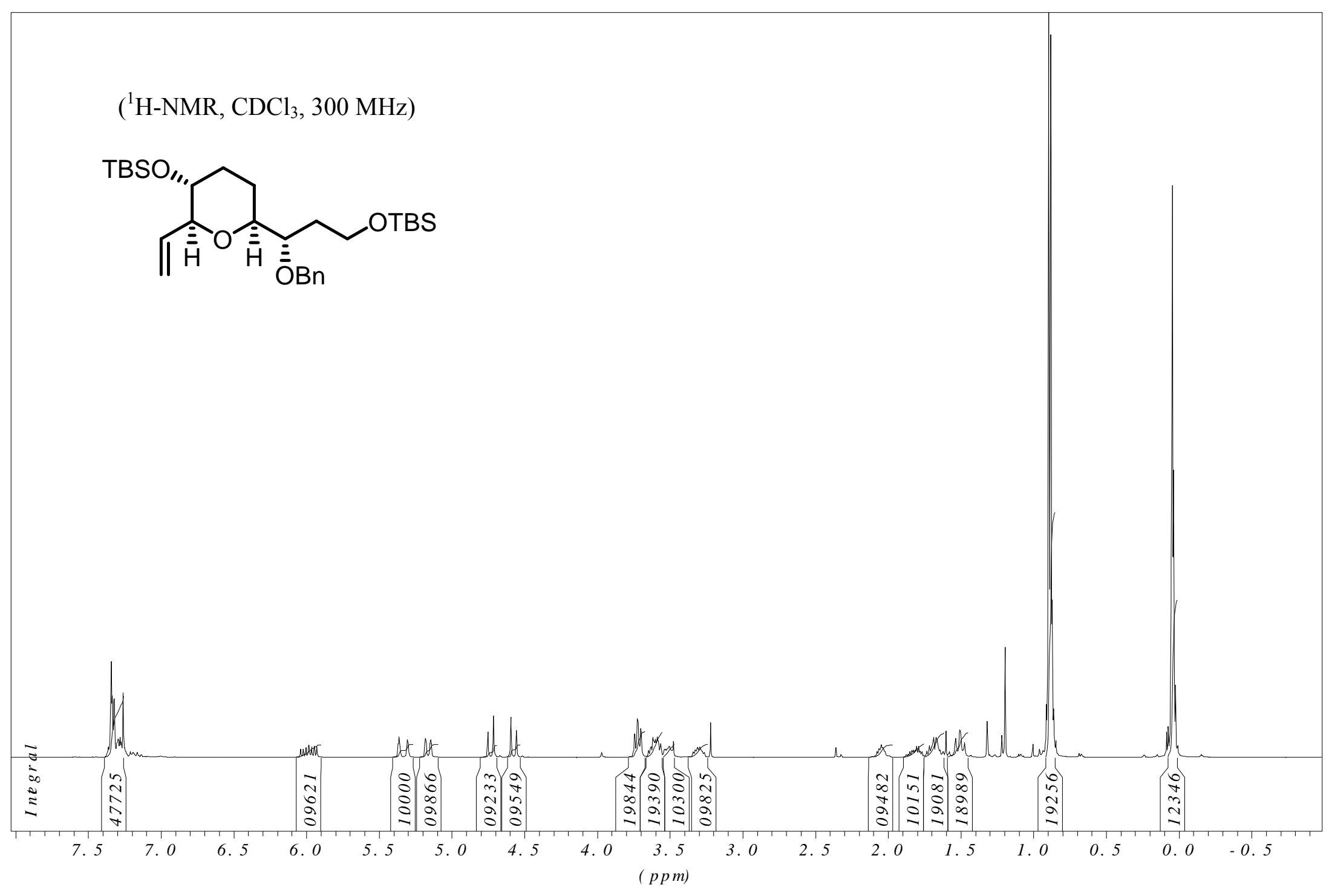




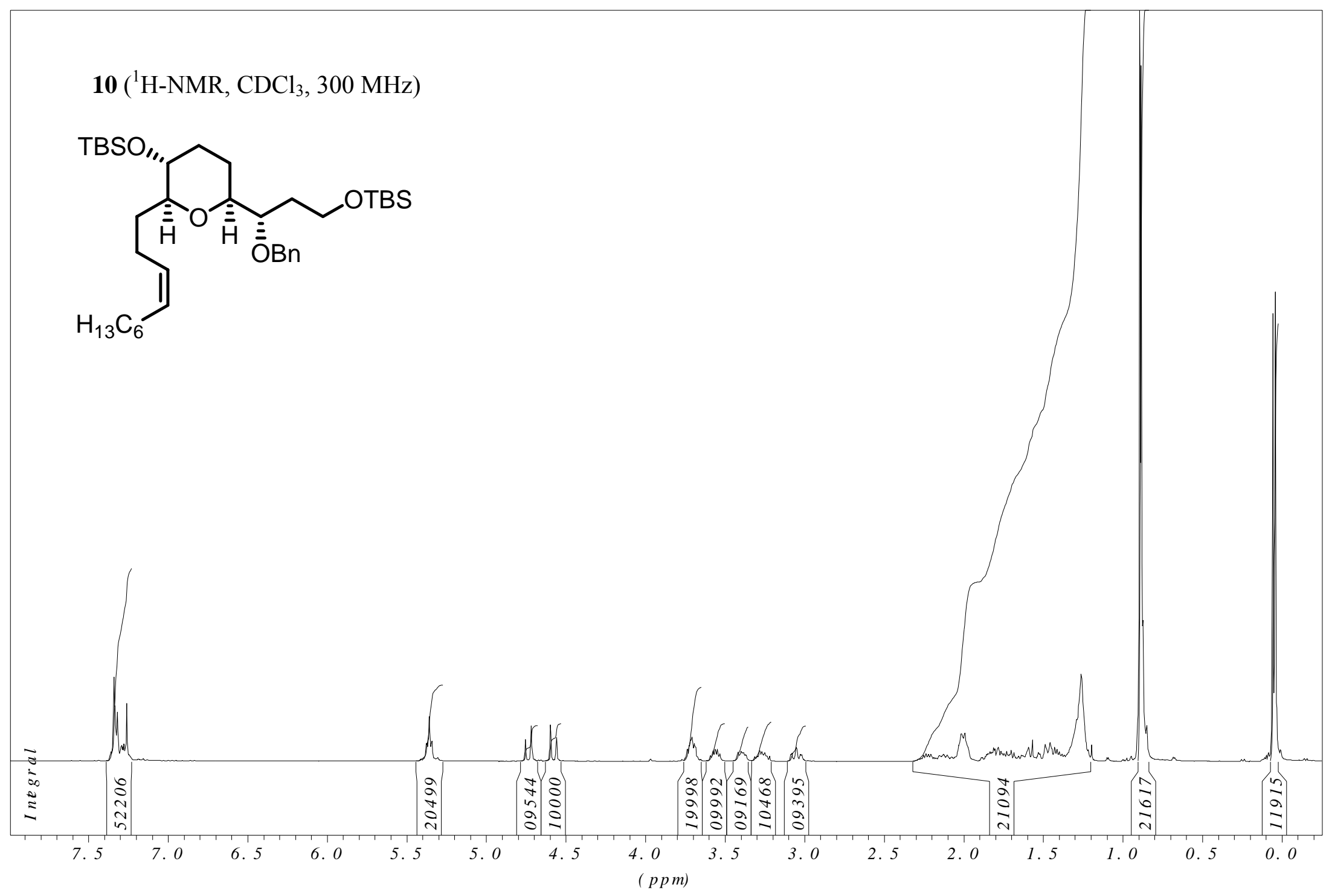




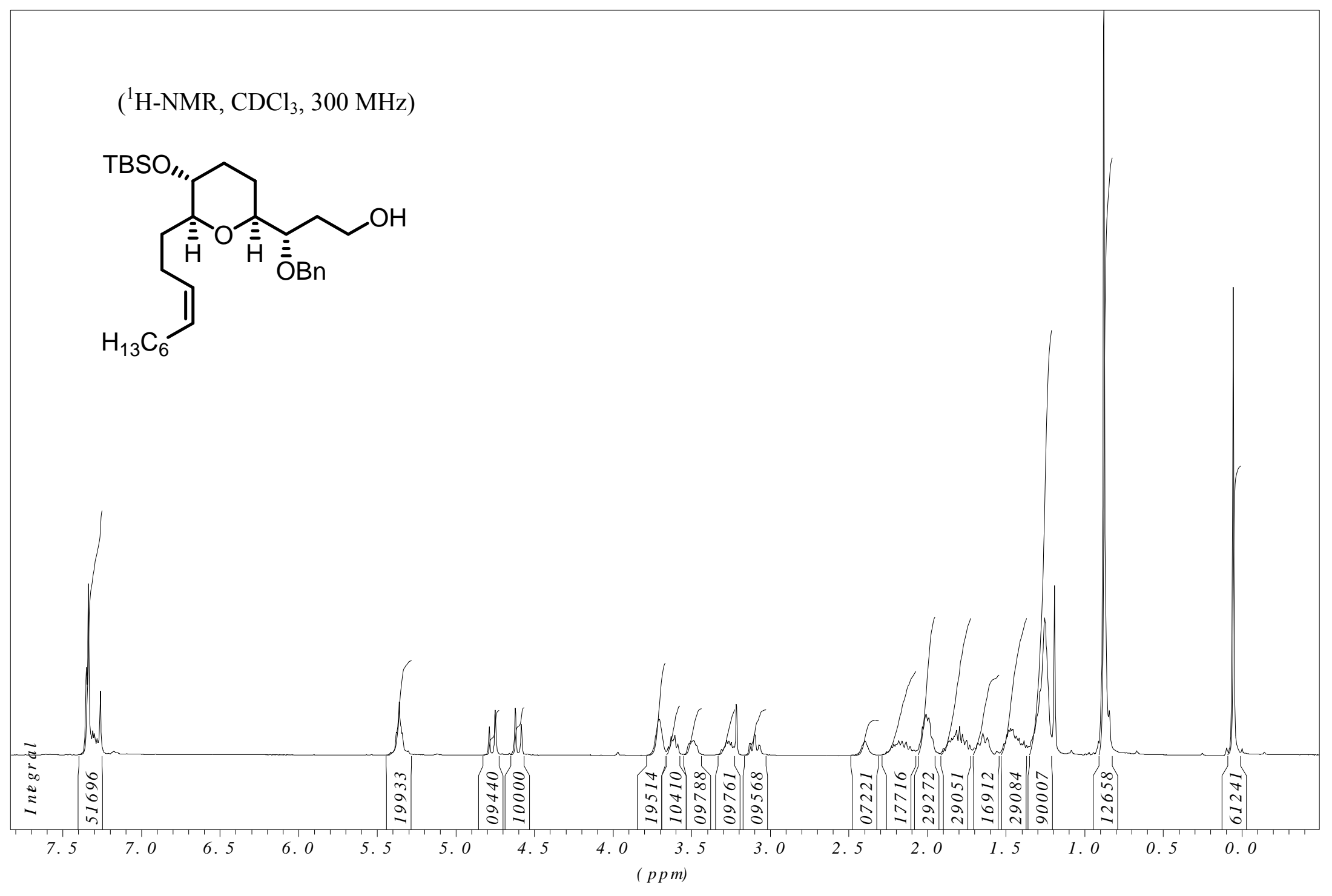




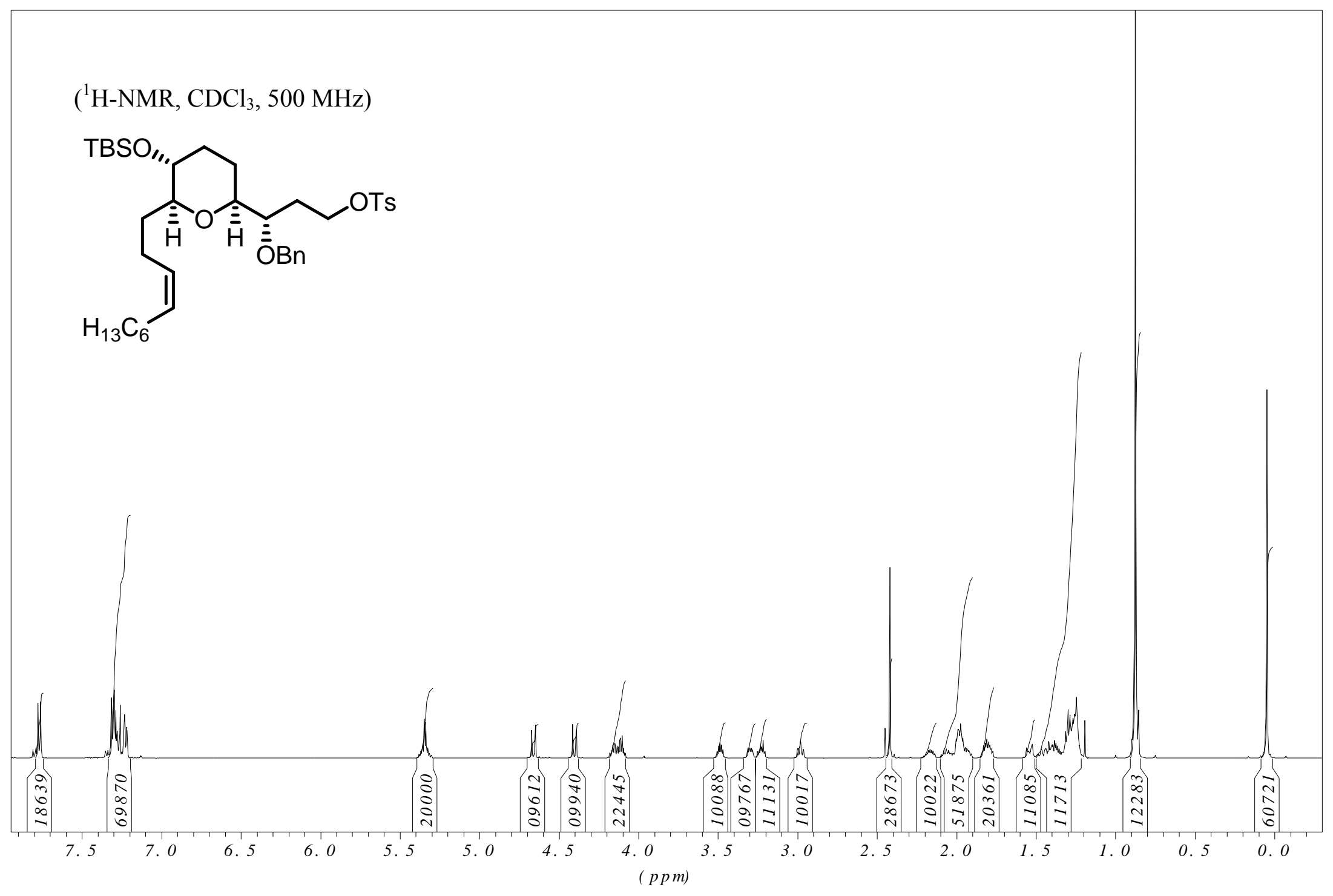




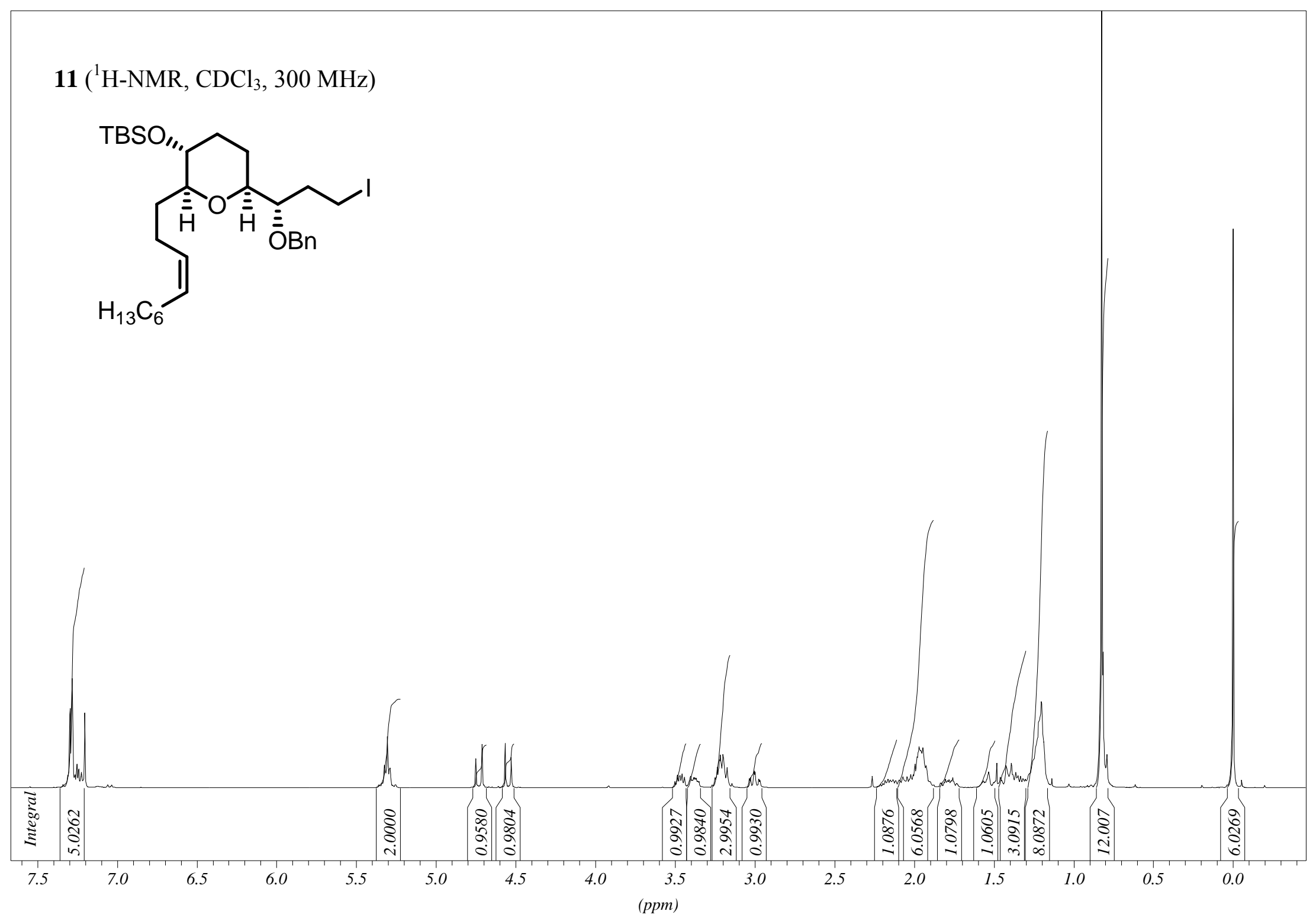




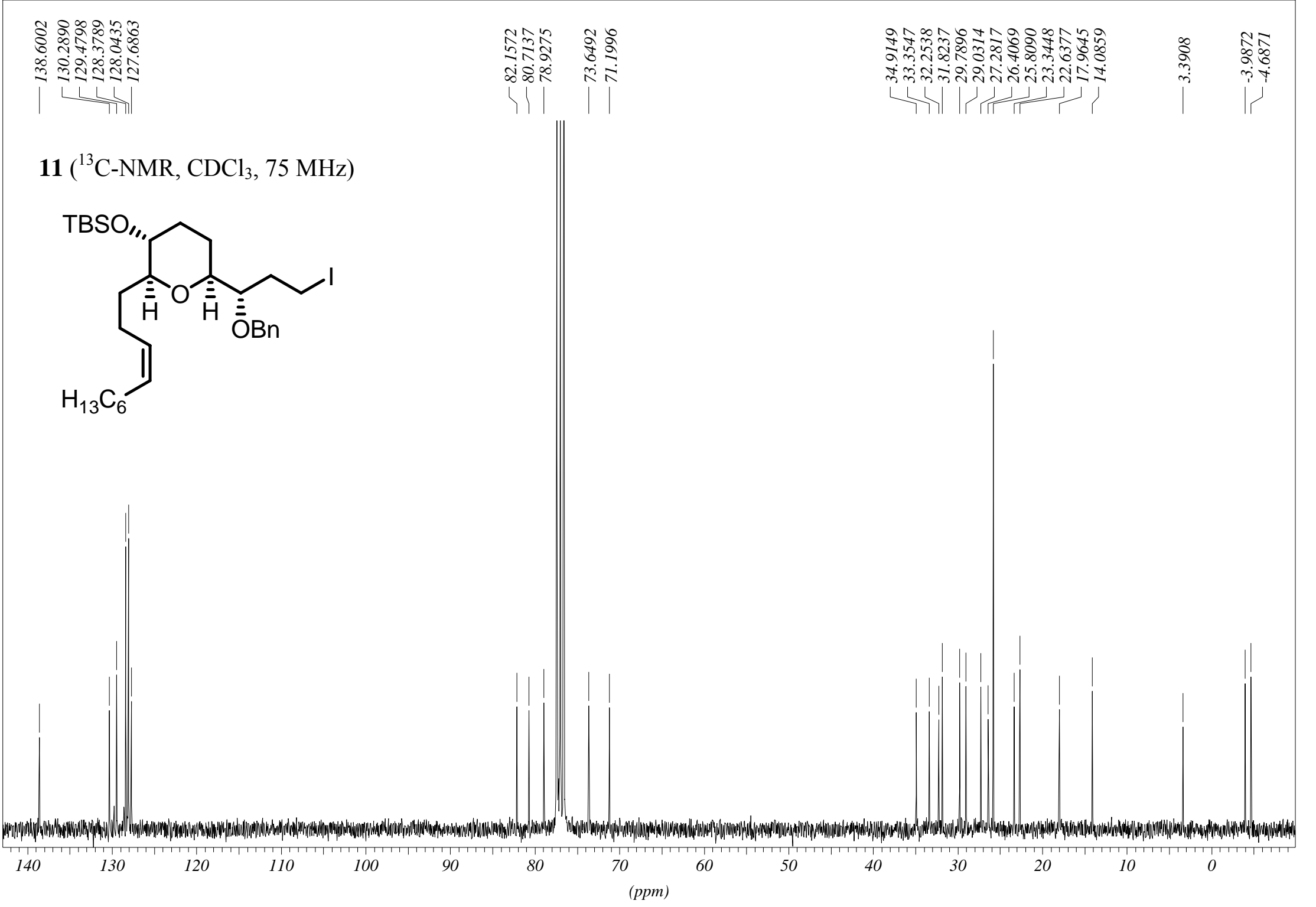




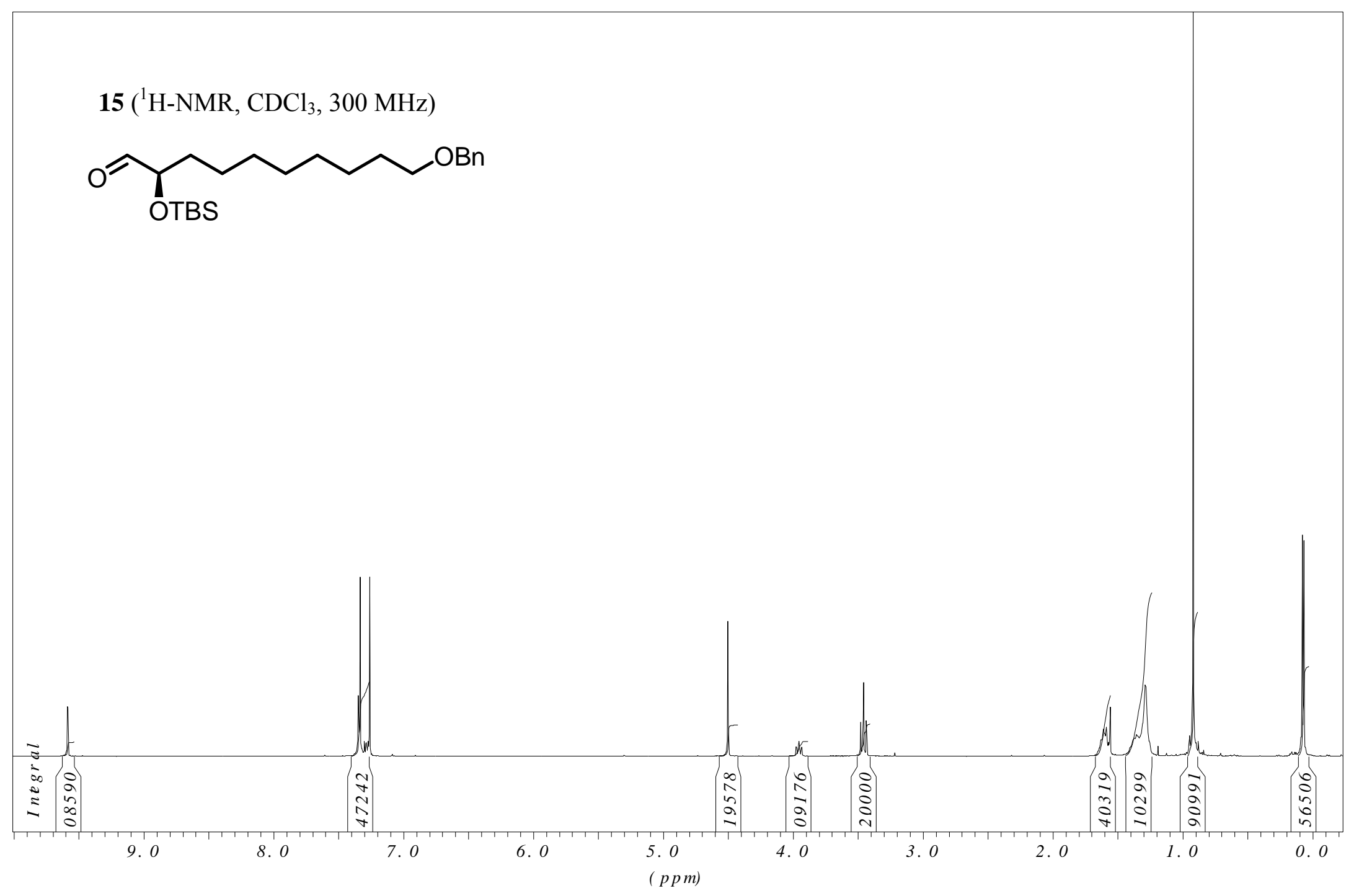




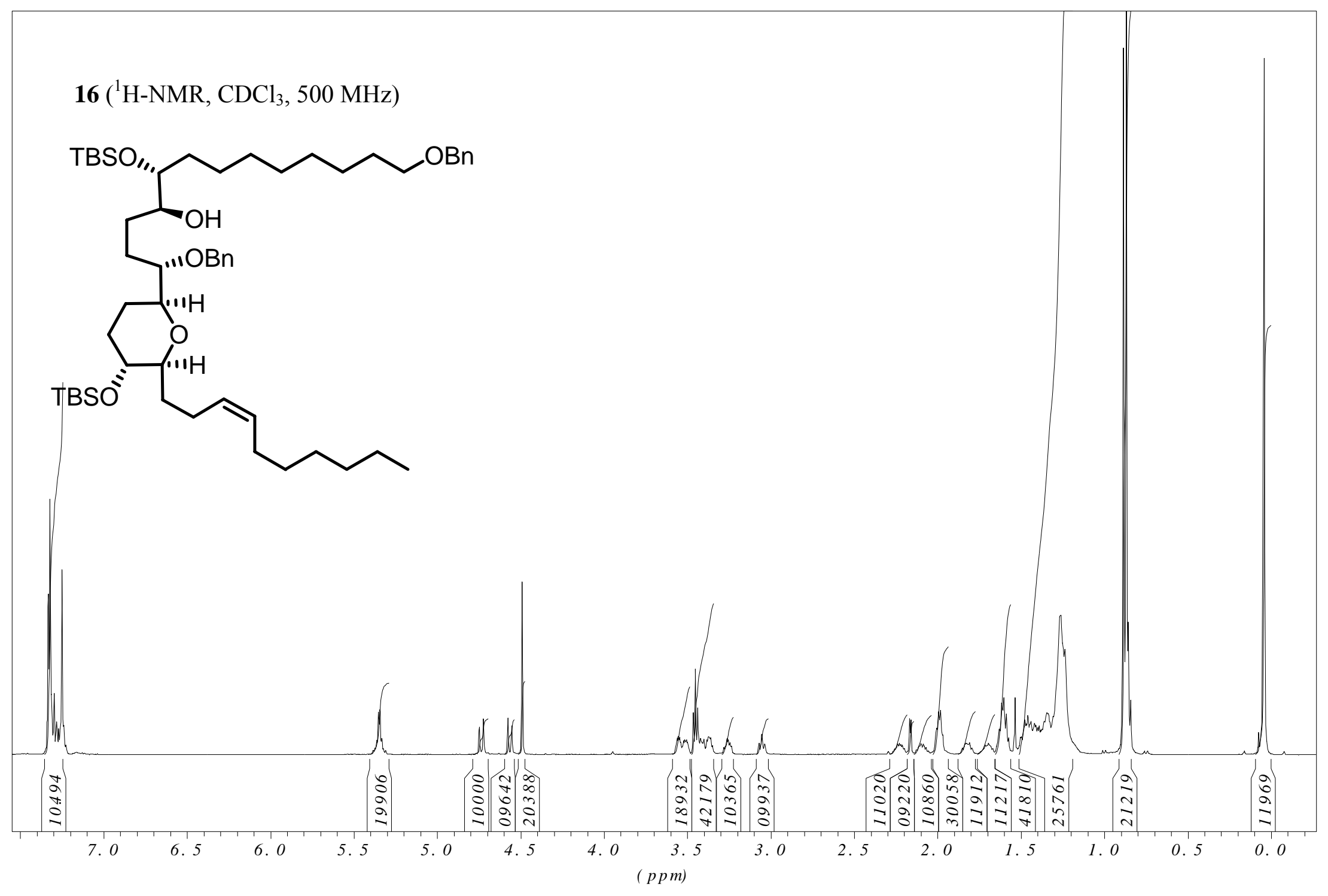




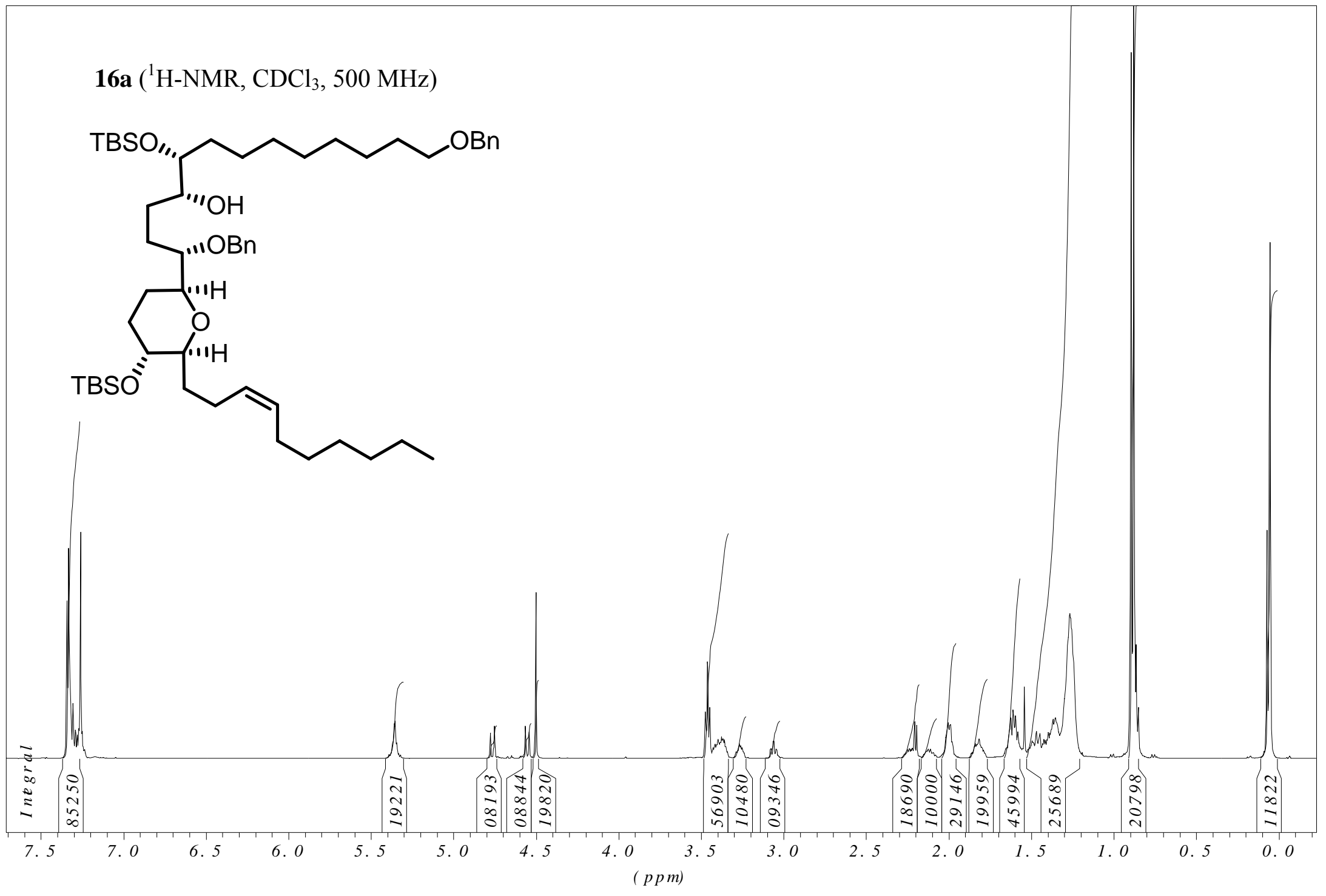




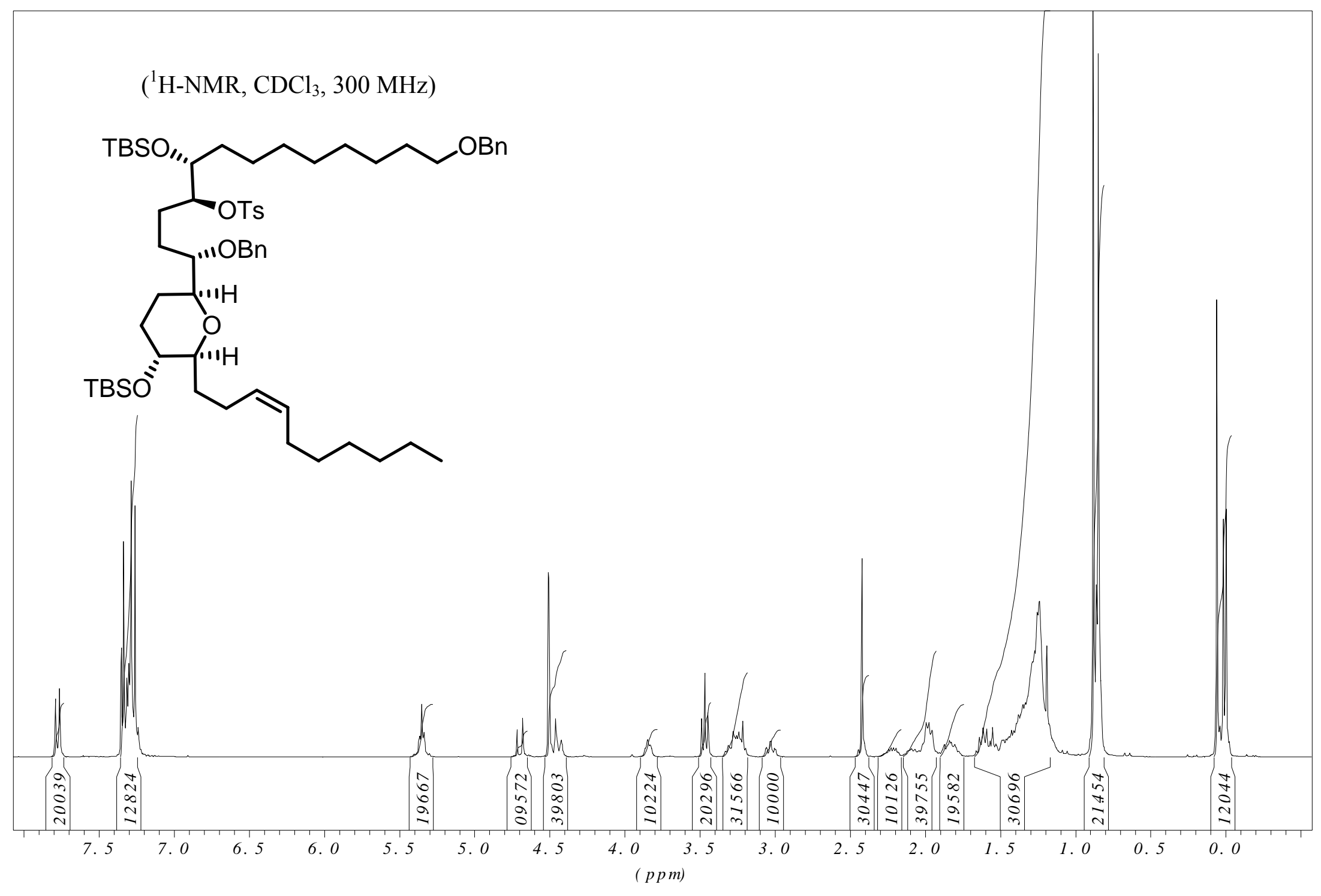


( ${ }^{1} \mathrm{H}-\mathrm{NMR}, \mathrm{CDCl}_{3}, 300 \mathrm{MHz}$ )
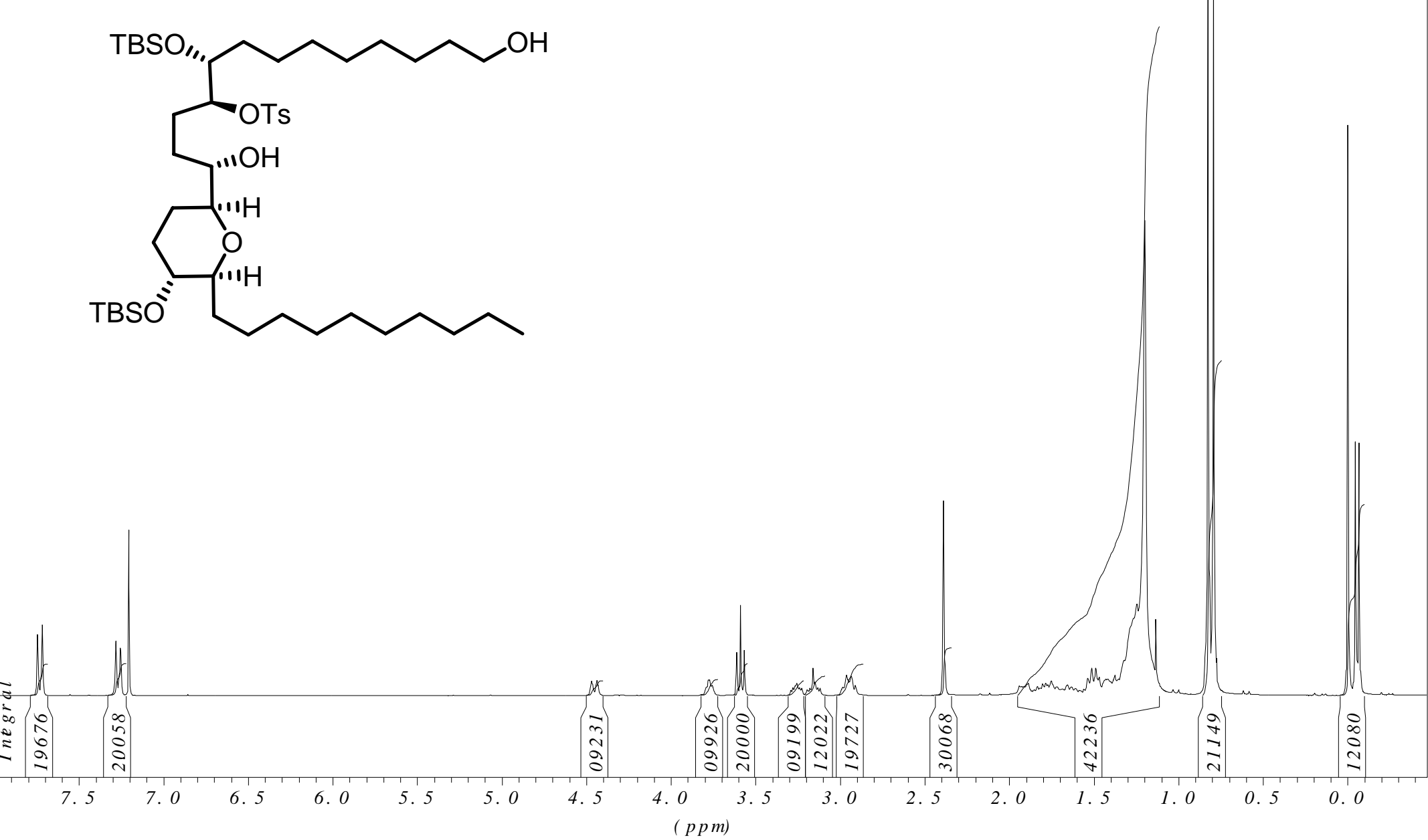


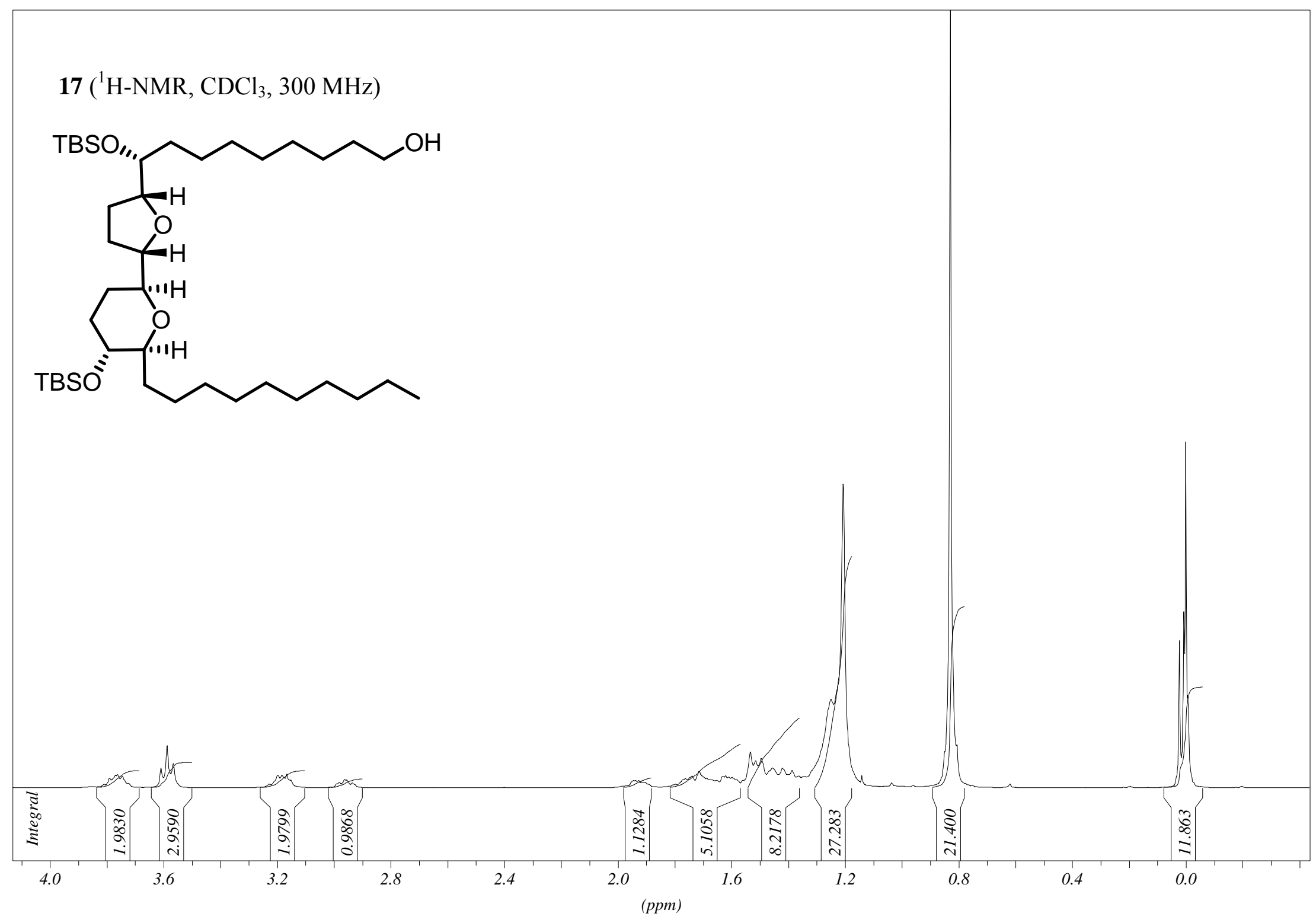




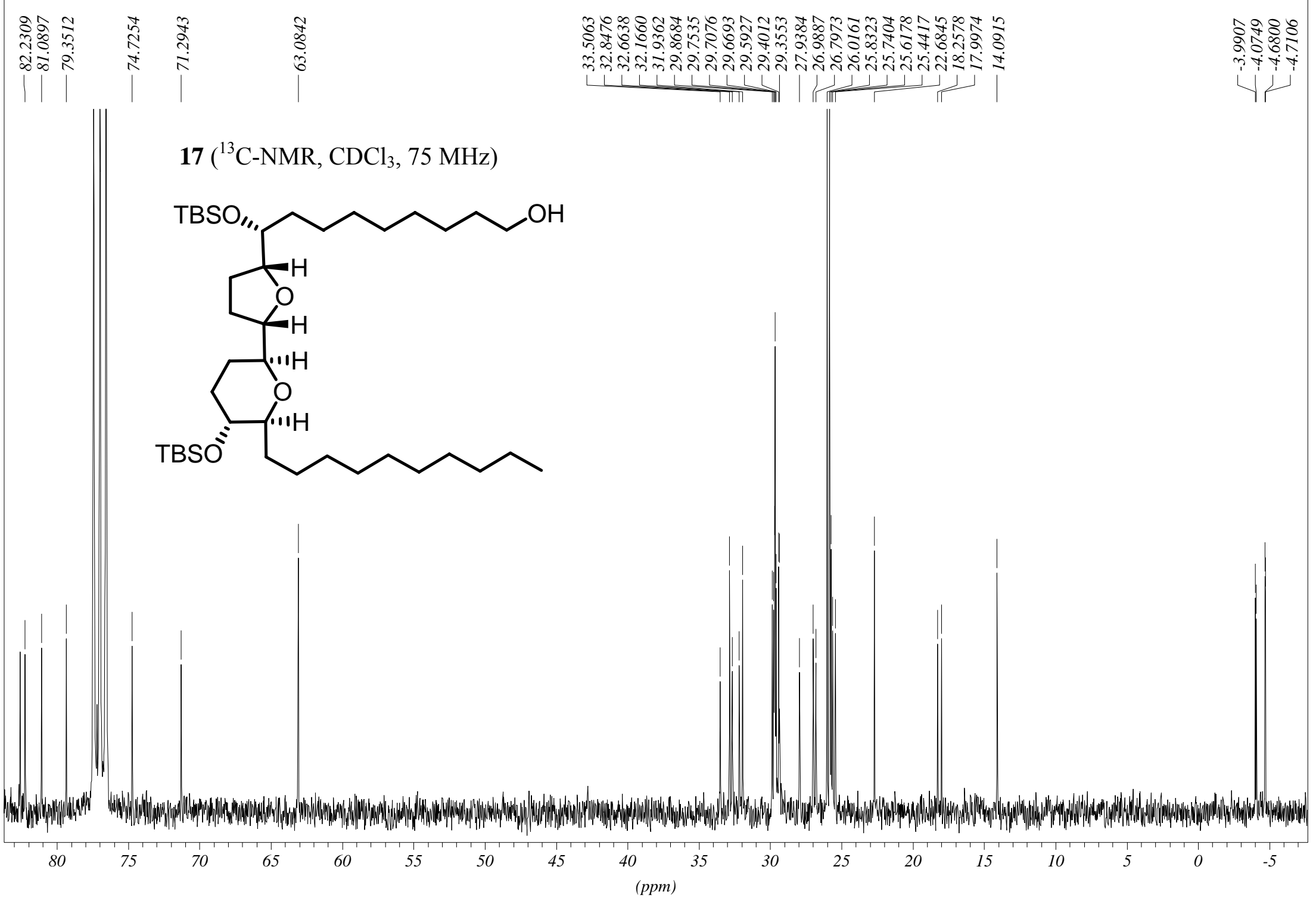




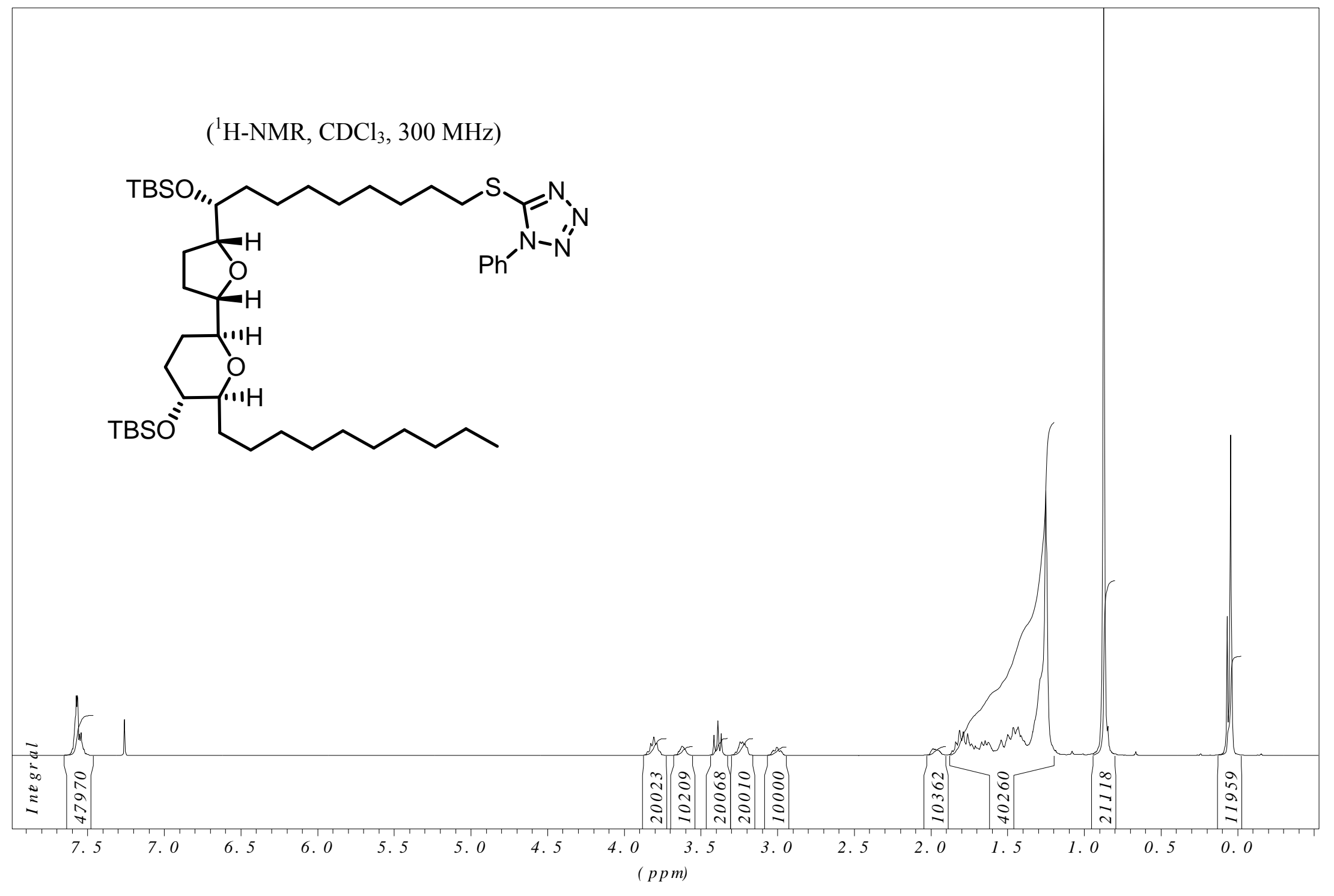




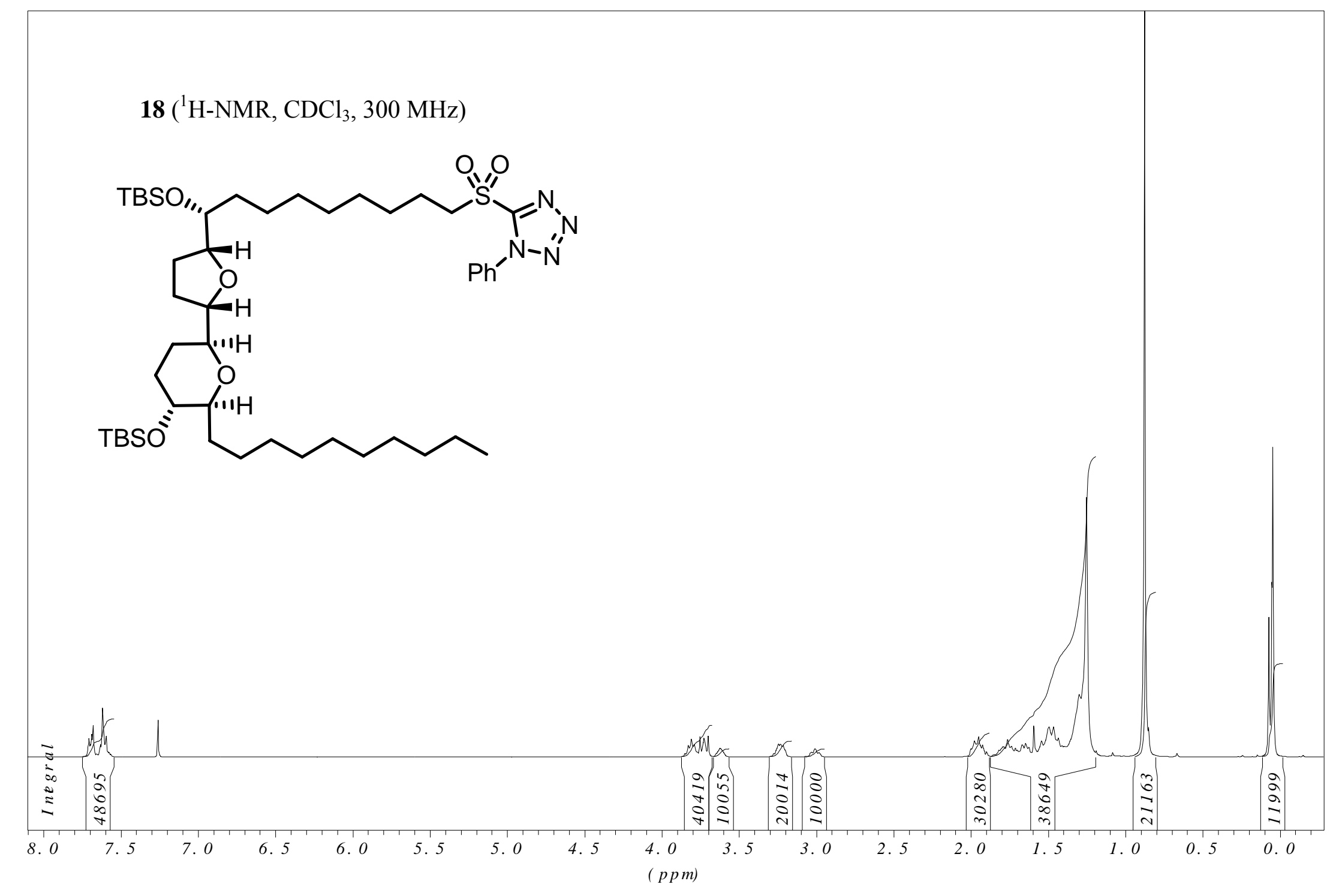


$20\left({ }^{1} \mathrm{H}-\mathrm{NMR}, \mathrm{CDCl}_{3}, 300 \mathrm{MHz}\right)$
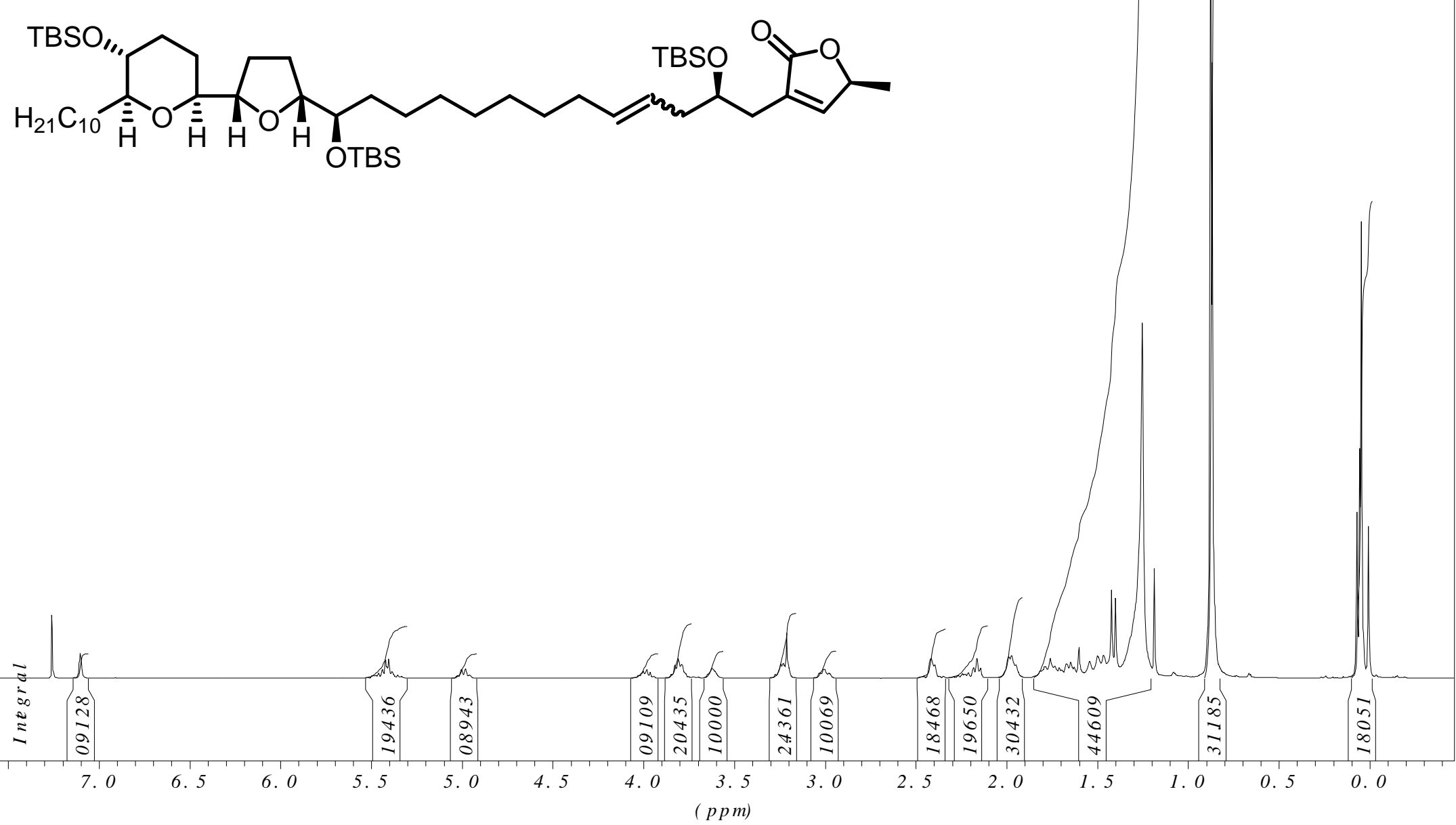


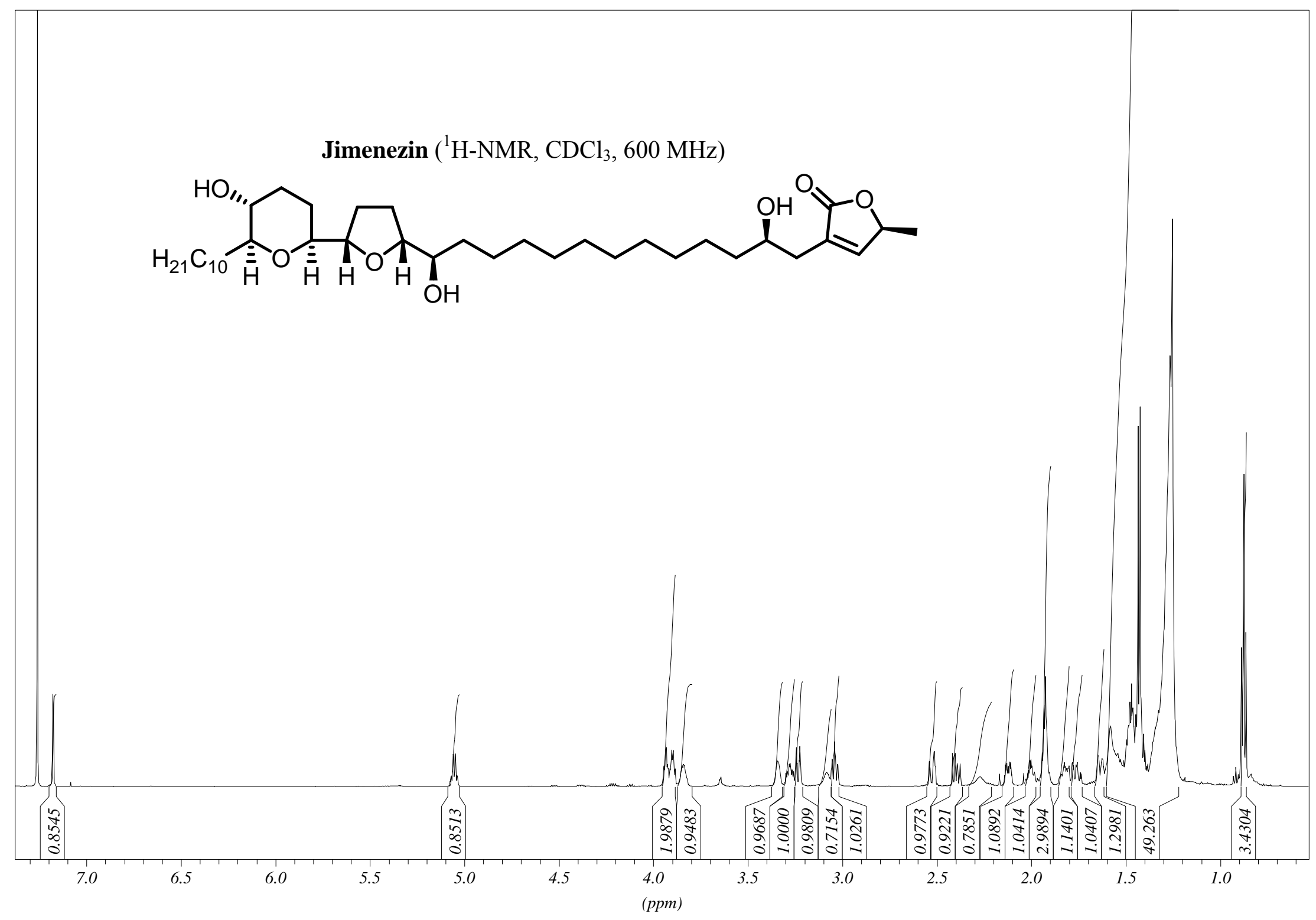




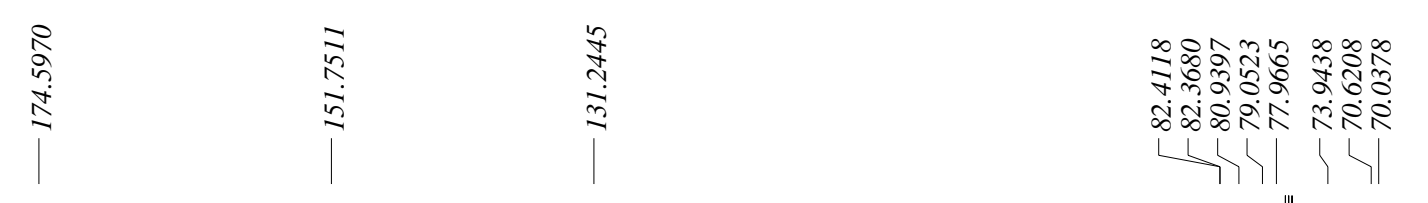

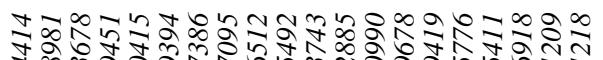

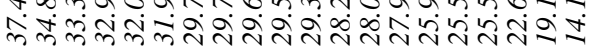

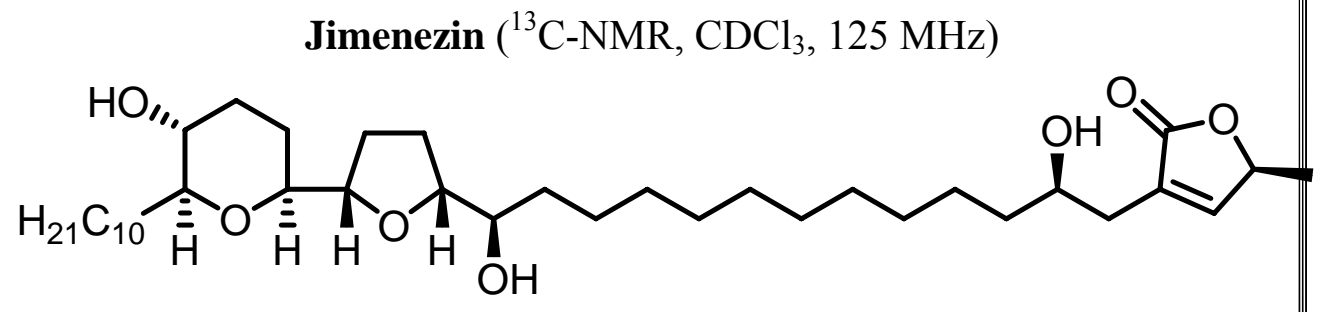

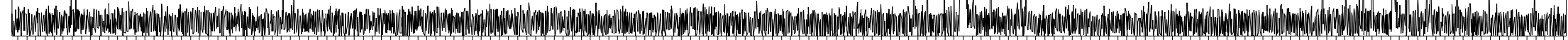

(ppm) 